\title{
Brain oscillatory activity associated with task switching and feedback processing
}

\author{
Toni Cunillera $\cdot$ Lluís Fuentemilla $\cdot$ Jose Periañez $\cdot$ Josep Marco-Pallarès • \\ Ulrike M. Krämer • Estela Càmara • Thomas F. Münte • Antoni Rodríguez-Fornells
}

Published online: 9 December 2011

(C) Psychonomic Society, Inc. 2011

\begin{abstract}
In this study, we sought to dissociate eventrelated potentials (ERPs) and the oscillatory activity associated with signals indicating feedback about performance (outcome-based behavioral adjustment) and the signals indicating the need to change or maintain a task set (rule-based behavioral adjustment). With this purpose in mind, we noninvasively recorded electroencephalographic signals, using a modified version of the Wisconsin card sorting task, in which feedback processing and task
\end{abstract}

T. Cunillera $\cdot$ J. Marco-Pallarès $\cdot$ A. Rodríguez-Fornells

Department of Basic Psychology, Faculty of Psychology,

University of Barcelona,

08035 Barcelona, Spain

L. Fuentemilla $\cdot$ J. Marco-Pallarès $\cdot$ E. Càmara $\cdot$

A. Rodríguez-Fornells

Cognition and Brain Plasticity Group (Bellvitge Biomedical

Research Institute) IDIBELL, L'Hospitalet de Llobregat,

Barcelona 08097, Spain

J. Periañez

Department of Basic Psychology II (Cognitive Processes),

Universidad Complutense de Madrid,

Madrid, Spain

U. M. Krämer • T. F. Münte

Department of Neurology, University of Lübeck,

23538 Lübeck, Germany

\section{A. Rodríguez-Fornells}

Institució Catalana de Recerca i Estudis Avançats (ICREA), Barcelona, Spain

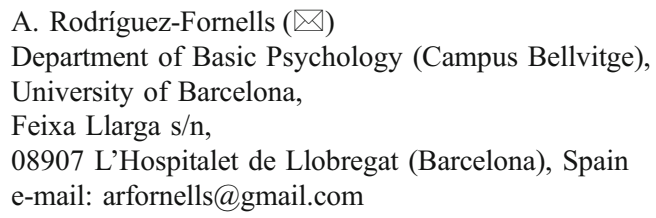

switching could be studied separately. A similar late positive component was observed for the switch and correct feedback signals on the first trials of a series, but feedbackrelated negativity was observed only for incorrect feedback. Moreover, whereas theta power showed a significant increase after a switch cue and after the first positive feedback of a new series, a selective frontal beta-gamma increase was observed exclusively in the first positive feedback (i.e., after the selection of the new rule). Importantly, for the switch cue, beta-alpha activity was suppressed rather than increased. This clear dissociation between the cue and feedback stimuli in task switching emphasizes the need to accurately study brain oscillatory activity to disentangle the role of different cognitive control processes.

Keywords Executive functions · Reinforcement learning · Task switching $\cdot$ Feedback processing $\cdot$ ERPs $\cdot$ Time frequency

\section{Introduction}

Our behavior is largely shaped by interactions with the environment. On the one hand, signals from the environment can be used to confirm (or disconfirm) whether an action was successful, thus optimizing behavior on a given task and strengthening a task set (outcome-based behavioral adjustment). On the other hand, environmental cues can also signal the need to change a task set and to use a different set of rules to process upcoming stimuli (rulebased behavioral adjustment). The ability to use environmental signals in such a flexible manner is part of the highlevel metacognitive executive functions, which include planning, problem solving, working memory, and perfor- 
mance monitoring (see Burgess, Veitch, de Lacy, \& Shallice, 2000; Damasio, 1995; Grafman \& Litvan, 1999; Shallice, 1988; Stuss \& Benson, 1986; Stuss, Shallice, Alexander, \& Picton, 1995). Although the relationship between the cognitive control mechanisms involved in taskswitching behavior and those related to reinforcement learning in the guidance of adjustment of intentional behavior has been implicitly (Logan, 1985; Miller \& Cohen, 2001; Norman \& Shallice, 1986; Posner \& Petersen, 1990; Stuss \& Benson, 1986) or explicitly (Botvinick, Braver, Barch, Carter, \& Cohen, 2001; Braver \& Ruge, 2005; Ridderinkhof, van den Wildenberg, Segalowitz, \& Carter, 2004) recognized in many previous studies, very few have directly compared their neural signatures.

The success or failure of cognitive control mechanisms relies on the activation strength of the task goal, although it is not yet clear what the key factors are that regulate this goal activation strength. Nevertheless, adaptive learning is thought to be based on the evaluation of positive and negative outcomes, and the consolidation of a task set may be facilitated by the same cognitive process. Thus, to optimize behavior for specific task demands, explicit information on the valence of the outcomes may be needed (Holroyd \& Coles, 2002). An implicit interplay between cognitive control and reinforcement learning mechanisms has been demonstrated in different studies. For instance, Cohen and Ranganath (2007) demonstrated that the magnitude of an event-related potential (ERP) signature associated with reinforcement learning predicted human behavior on a decision-making task. In a similar vein, it has been proven that changes in motivational state (driven by the manipulation of the valence of incentives) modulate behavioral performance as it is further reflected in the modulation of neural activity in areas belonging to the cognitive control network (Locke \& Braver, 2008). Thus, the delivery of reward in relationship to the achievement of behavioral goals implicates a larger engagement of the underlying cognitive processes necessary for such goal achievement (Jimura, Locke, \& Braver, 2010; Savine \& Braver, 2010). This facilitatory effect of reward on task set strengthening may be accomplished by the dynamic and flexible engagement of cognitive control mechanisms operating in distributed brain regions.

To study the interplay of task switching and feedback processing, we exposed participants to a modified version of the Wisconsin Card Sorting Task (WCST), a widely used task in clinical neuropsychology that requires participants to flexibly adapt their behavioral responses to simple geometrical stimuli on the basis of the signals provided by the experimenter (Braver \& Ruge, 2005; Heaton, 1981; Heaton, Chelune, Talley, Kay, \& Curtiss, 1993; Milner, 1963; Stuss \& Picton, 1978). In particular, the WCST requires participants to establish, maintain, and shift classification rules or task sets (i.e., the color, shape, or number of the elements displayed on a target card by which it could be matched with one of four key cards), on the basis of positive (correct) and negative (incorrect) feedback provided by the examiner. Several functional neuroimaging studies using the WCST have revealed the activation of a widely distributed brain network encompassing several prefrontal regions (i.e., inferior frontal gyrus, dorsolateral prefrontal cortex, anterior cingulate cortex) and posterior association areas (i.e., supramaginal gyrus, intraparietal sulcus) when task sets need to be changed (Konishi et al., 1998; Monchi, Petrides, Petre, Worsley, \& Dagher, 2001; Nagahama et al., 1997; Volz et al., 1997). In addition, the dynamics of this frontoparietal network have also been studied using ERPs and magnetoencephalographic (MEG) recordings, which revealed an amplitude enhancement of a frontoparietal P3-like component in response to signals indicating the need of a task switch (Barceló, Periañez, \& Knight, 2002; Furumoto, 1991; Periáñez et al., 2004; Stuss \& Picton, 1978; Watson, Azizian, \& Squires, 2006). Accordingly, many authors have interpreted the switch-P3 enhancement in the ERPs as the neural signature of a cognitive control mechanism required for task set reconfiguration during task switching (Brass, Ullsperger, Knoesche, von Cramon, \& Phillips, 2005; Kieffaber \& Hetrick, 2005; Kopp, Tabeling, Moschner, \& Wessel, 2006; Lai \& Mangels, 2007; Nicholson, Karayanidis, Poboka, Heathcote, \& Michie, 2005; Rushworth, Passingham, \& Nobre, 2002; Slagter, Kok, Mol, Talsma, \& Kenemans, 2005; Swainson, Jackson, \& Jackson, 2006).

There is, however, an inherent confound when the original task design is used, since, on the one hand, the same kind of feedback is used to signal the correctness or incorrectness of a response and, on the other hand, there is a need to switch task sets. In other words, the demands for adjusting behavior on the basis of outcome-based and rulebased signals are mixed. Thus, the brain correlates in the original WCST are similarly ambiguous. An important step toward clarifying the neural correlates of task set switching in the WCST has been made by several studies that have avoided the use of explicit positive and negative feedback and, instead, have introduced cuing signals (i.e., auditory tones) to indicate whether to switch or to repeat the preceding task rule (Periañez et al., 2004). Nevertheless, even in this setup, reinforcement learning mechanisms could be taking place during the cuing period, since participants could adjust their correct or incorrect predictions of their previous response on the basis of repeat and switch cues, respectively. In another set of task-switching and WCST studies, cues signaling a readjustment of the task rule and cues signaling the correctness of the performance have been separated and introduced in distinct stages of the trial series (Adrover-Roig \& Barceló, 2010; 
Jost et al., 2008; Kieffaber \& Hetrick, 2005; Periañez \& Barceló, 2009). In all of these studies, however, the analyses of the electrophysiological responses elicited by the feedback signals have been omitted. In the present experiment, we analyzed two types of signals presented to the participants: (1) cue signals that indicated that the participants should either repeat the same sorting rule or switch to another rule at the beginning of each trial (rulebased behavioral adjustment) and (2) feedback signals after the button (sorting) response indicating the correctness of the participants' responses (outcome-based behavioral adjustment).

Whereas the excellent temporal resolution of the ERPs is undisputed, the time domain analysis of the EEG has yielded very similar P3-like ERP responses to signals indicating task switching (Barceló et al., 2002; Nicholson et al., 2005; Rushworth et al., 2002; Stuss \& Picton, 1978) and feedback signals (Chwilla \& Brunia, 1991; De Swart, Kok, \& Das-Smaal, 1981; Haschke, Haschke, Schwind, Dormann, \& Dormann, 1985; Holroyd, Pakzad-Vaezi, \& Krigolson, 2008; Johnson, 1986; Johnson \& Donchin, 1978; Kotchoubey, 2002; Müller, Moller, RodríguezFornells, \& Münte, 2005). Importantly, ERP averaging is blind to activity that is not phase locked to the eliciting stimulus, which is particularly important for highfrequency responses (i.e., $>20 \mathrm{~Hz}$ ). Wavelet-based singletrial time frequency (TF) EEG analysis has the potential to overcome this shortcoming. For example, a frontocentral beta-gamma (i.e., 20-30 Hz) frequency band component has been recently associated with positive feedback processing (Cohen et al., 2007; Haji Hosseini, Rodríguez-Fornells, \& Marco-Pallarès, 2011; Marco-Pallarès et al., 2008; MarcoPallarès et al., 2009; van de Vijver, Ridderinkhof, \& Cohen, in press), which was not present on the standard ERP analysis. This modulation of positive monetary feedback affected partially high-beta and low-gamma bands. This beta-gamma component was initially interpreted as a possible neural signature of reward that is involved in the synchronization of neural regions over long distances to couple frontal and striatal structures involved in reward processing. Importantly, at least two recent studies have shown (1) that the amplitude of this beta-gamma component depends on the amount of unexpectancy of the positive feedback (Haji Hosseini et al., 2011) and (2) that it predicts the amount of learning after the appearance of the feedback (van de Vijver et al., in press). Thus, previous studies suggest an important role of beta-gamma oscillatory activity in processing important or novel positive information that is required to improve learning or future behavioral adjustments. In addition, a follow-up study showed a potential role of dopamine in this positive reward-related response (Marco-Pallarès et al., 2009).
The feedback-related negativity (FRN) has been identified as a neural signature that is specifically evoked after a negative feedback is delivered, indicating that an outcome is worse than expected. Thus, the FRN has been recorded from the medial-frontal scalp regions with the presentation of feedback informing of an incorrect performance (Holroyd \& Coles, 2002; Müller et al., 2005) or with feedback signals indicating the amount of money lost in a gambling task (Gehring \& Willoughby, 2004). Furthermore, it has been found that the appearance of the FRN is accompanied by an increment of neural oscillations in the theta range (4-8 Hz) (Cohen, Elger, \& Ranganath, 2007; Marco-Pallarès et al., 2008). Thus, the neural origins of the high-level error-processing system involved in action monitoring and behavioral adjustments could be, at least, partially oscillatory in their origin (Cavanagh, Cohen, \& Allen, 2009; Cavanagh, Frank, Klein, \& Allen, 2010; Cohen et al., 2007; Marco-Pallarès et al., 2008).

Only a few studies have dealt with oscillatory EEG analysis of task switching. Nonetheless, the results obtained in different studies are congruent and highlight the importance of the theta and alpha band activity in switching between task sets. For example, Gladwin and de Jong (2005) found that while theta power increased in switch trails, as compared with repeat trials, the alpha activity decreased. This same pattern of results was also reported by Sauseng et al. (2006), who interpreted the specific increase in theta activity as reflecting a search process in long-term memory and the decrease of the alpha activity as representing the retrieval of information from long-term memory. The importance of the alpha suppression in task switching is further supported by the results reported by Verstraeten and Gluydts (2002), who found that alpha suppression was positively correlated with task performance.

Monsell (2003; see also Rogers \& Monsell, 1995) postulated that in task switching, a reconfiguration of task sets must be implemented. This reconfiguration process is described as comprehending a diverse set of cognitive operations, such as shifting attention between stimulus attributes, retrieving action and conditional goals from memory, and inhibiting the elements of the previous task set, with all of these processes being necessary to adjust response criteria to a distinct response set (Monsell, 2003). Thus, the modulation of theta and alpha oscillatory activity might be indicative of the occurrence of some of the previously listed cognitive processes.

The present study used TF analysis, in addition to ERP analysis, to disentangle the neural correlates of feedback and task-switching signals during WCST performance. As a working hypothesis, we expected to find analogous P3 ERP responses to cue and feedback signals and a specific FRN and a theta power enhancement to negative feedbacks 
(Cohen et al., 2007; Gehring \& Willoughby, 2004; Holroyd \& Coles, 2002). Moreover, we expected to replicate the results obtained in previous task-switching studies (Gladwin \& de Jong, 2005; Sauseng et al., 2006) that reported an increase in theta and a decrease in alpha activity specifically for the task-switching process. Finally, we predicted a specific response in the beta-gamma band to positive feedback (Cohen et al., 2007; Marco-Pallarès et al., 2008), reflecting the recruitment of the neural network involved in feedback processing, which was expected to be absent after task-switching cue signals. Moreover, considering two recent studies (Haji Hosseini et al., 2011; van de Vijver et al., in press), we expected that the increase in betagamma oscillatory activity would be selective for those positive feedback trials that were needed for learning purposes and to strengthen the new task set correctly chosen among the alternatives.

\section{Method}

\section{Participants}

Thirty-eight undergraduate students (25 female, 13 male; age $[M \pm S D], 21.5 \pm 3.7$ years; age range $=18-34$ years) took part in the experiment. They all had normal or corrected-to-normal visual acuity, presented no history of neurological or psychiatric disorders, and were recruited from advertisements placed on university billboards in the city of Barcelona. Participants signed a consent form according to the Declaration of Helsinki and were informed about the purpose of the investigation prior to the experimental session. Participants were paid for their participation.

\section{Stimuli and procedure}

A modified version of the WCST task was used (Fig. 1a). Each trial began with an auditory cue signaling either to repeat the rule used on the previous trial (65-dB tone; 250 ms duration; $2000 \mathrm{~Hz}$ ) or to switch to a different one (500 $\mathrm{Hz}$ ). The cue was followed 1,000-1,700 ms later by a visual target display, which contained 1 of 24 target cards centered on the computer monitor and the four WCST key cards above. No time limit for acquiring participants' responses was introduced in the task, and therefore, the target display remained on the screen until a response was given. Responses were made with a four-button panel corresponding to the layout of the four key cards that had to be pushed with the index and middle fingers of both hands. Feedback was provided $1,000 \mathrm{~ms}$ after the responses (duration, 1,000 ms), indicating a correct or incorrect performance by a smiling or a sad smiley icon. A fixed interval of $300 \mathrm{~ms}$ was adopted between the offset of feedback and the occurrence of the next cue event.

A total of 234 trials was presented and arranged in 39 series. Each series consisted of a variable number of trials requiring the same sorting principle (i.e., color, shape, or number). The length of each series varied randomly between 5 and 7 trials such that the participants could not predict the start of a new series (i.e., 13 series of 5, 6, and 7 trials). The 24 target cards were repeatedly used across the task, and their order was determined randomly within the series. The succession of task rules was randomly set for each participant, and consequently, participants could not predict the succession of rules along the experiment. Importantly, participants were not informed about the initial sorting rule.

A valid series was scored if (1) the participant found the task rule on either the first or the second trial in the series and (2) the task rule was not missed thereafter. With regard to the first criterion, it is important to note that because the sorting principle changed after a random number of trials (from five to seven), the participants had to make a guess after the first shift cue of a new series, which had a $50 \%$ chance to be wrong. These first-trial errors were thus defined as guess errors whenever they involved a shift in the rule and were followed by correct sorts on all remaining trials of that series. Therefore, only series with a correct shift after the switch cues or series with guess errors on the first trial were considered as valid series. Series with any errors other than the initial guess error were considered failed series and were excluded from the analysis of reaction times (RTs) and electrophysiological brain responses. Therefore, only correct trials in all of the series were considered for the analyses, with the only exception being trials containing a switch error, which were retained for the analysis of behavioral accuracy and brain processing of negative feedback.

Participants were informed in detail about the task prior to the experimental session. Thus, the subjects were requested to find the sorting rule (color, shape, or number), to classify the target card on the basis of one of the three rules, and, finally, to rely on feedback to determine the correctness of their responses. Participants were also informed about the presentation of the auditory cues at the beginning of each trial indicating that they should switch or repeat the sorting rule used on the previous trial. The experiment began after the experimenter made sure that the participants had perfectly understood the task. A break was taken after 12 series had been completed. Importantly, only on the trials following the breaks, the three rules were available again as the correct sorting rule, and consequently, responses had a $33 \%$ chance of being wrong. Participants were encouraged to minimize blinking. The experiment lasted for approximately $30 \mathrm{~min}$. The first two 
A.
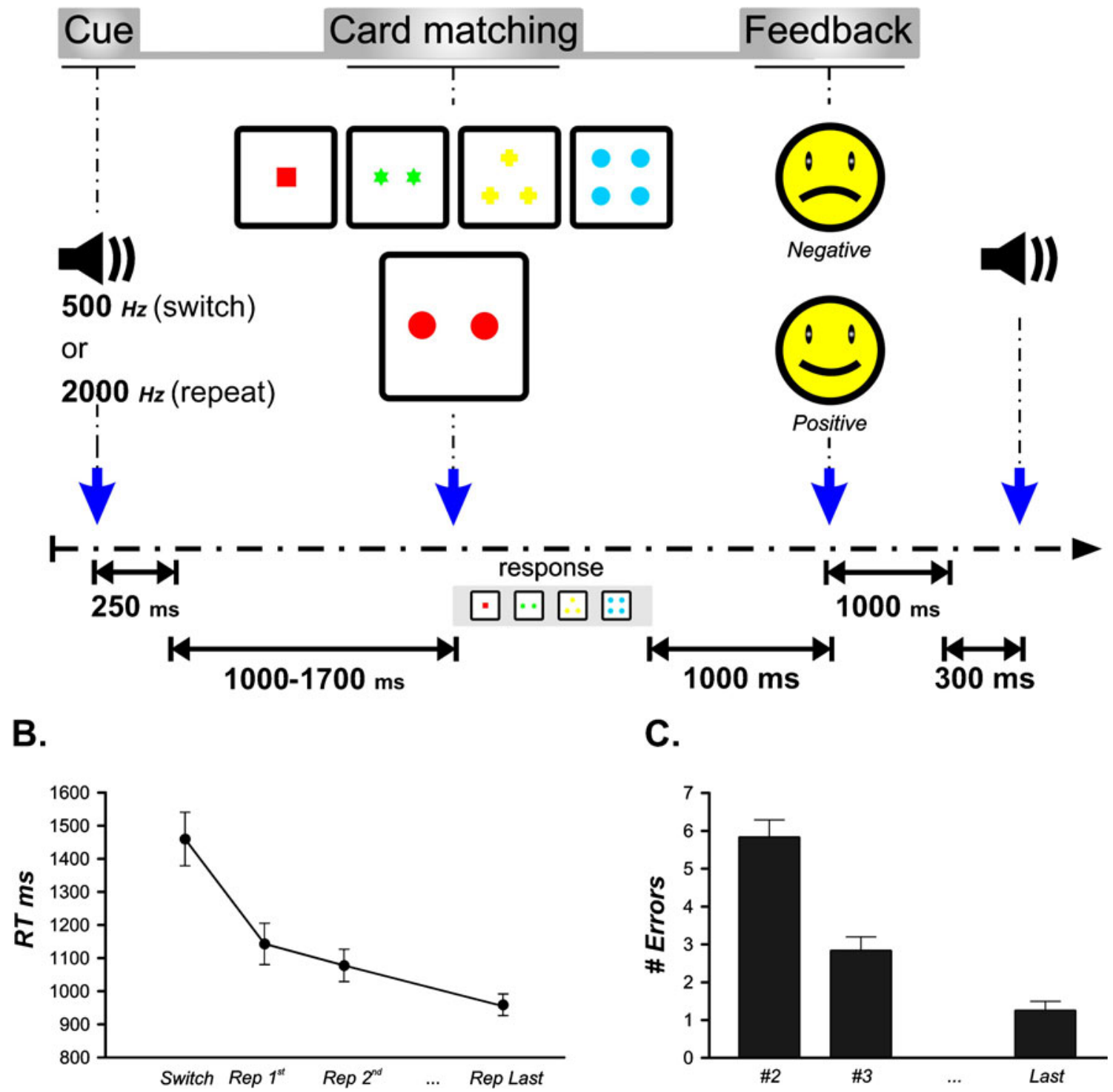

Fig. 1 a Schematic illustration of the trial structure in the modified version of the Wisconsin card sorting task (WCST), which includes the feedback signal. Participants were instructed to match a target card centered in the computer monitor with one of the four key cards on top following one of the three possible sorting rules: number, color, or shape of elements in the cards. At the beginning of each trial, an auditory cue indicated either switching or repeating the rule used on

series of the experiment were always used as practice trials to minimize the amount of errors. This short habituation with the task was motivated by the short duration of the experiment. Therefore, to maximize the signal-to-noise ratio of the EEG data, we opted to minimize the amount of trials considered as practice ones. In subsequent behavioral analyses, based on RT measures, we further confirmed that including the first two series of the experiment as a training set helped to homogenize behavioral changes that could be explained merely by the the previous trial. One second after each response, information about the correctness of the rule selection was provided by means of a positive or a negative visual feedback. b Mean reaction times $( \pm S E M)$ from completed WCST series (solid circles). c Mean percentage of errors from failed WCST series (bars) according to their serial positions in the series (second, third, and last trials)

familiarization process for the task (data not shown). Consequently, data acquired from the two practice series were not included in the analyses.

Behavioral analyses

RTs were separately measured for correct trials in valid series for switch and repeat trials and according to the serial position of the trials (trial type: switch, 1st Rep, 2nd Rep, and last Rep). These were subjected to a 
repeated measures ANOVA with trial type as the main factor

An ANOVA on the number of errors as defined above was performed to measure accuracy. The main trial type factor had three levels according to the position of the errors within the series (trial 2, 3, or last). Guess errors on the first trial were not considered for analysis of negative feedback signals.

\section{Electrophysiological recordings}

The ERPs were recorded using tin electrodes mounted in an elastic cap (Electro-Cap, International) and located at 29 standard positions (Fp1/2, Fz, F7/8, F3/4, Fc1/2 Fc5/6, Cz, C3/4, T3/4, Cp1/2, Cp5/6, Pz, P3/4, T5/6, Po1/2, O1/2). Electrode impedances were kept below $5 \mathrm{kOhm}$. Biosignals were referenced online to the average signal of all 29 electrodes and then rereferenced offline to the mean of the activity at the two mastoid processes. The electrophysiological signals were filtered with a bandpass of $0.1-70 \mathrm{~Hz}$ (half-amplitude cutoffs), a notch-filter $(50 \mathrm{~Hz})$, and digitized at a rate of $250 \mathrm{~Hz}$. Vertical eye movements were monitored with an electrode at the infraorbital ridge of the right eye. Trials with a base-to-peak electro-oculogram (EOG) amplitude of more than $50 \mu \mathrm{V}$, amplifier saturation, or a baseline shift exceeding $200 \mu \mathrm{V} / \mathrm{s}$ were automatically rejected offline.

\section{ERPs analyses}

Stimulus-locked ERPs for correct artifact-free trials (minimum of 20 trials, averaged per participant) were averaged over epochs of $1,024 \mathrm{~ms}$, including a 100 -ms prestimulus baseline. This was performed separately for the cue stimulus for the first switch trial (switch), the first repeat trial (1st Rep), the second repeat trial (2nd Rep), and the last trial of the series (last Rep). Feedback-locked ERPs (1,024-ms epoch starting $100 \mathrm{~ms}$ prior to the feedback) were also separately obtained on correct trials for the different serial positions of positive feedback events (1st $\mathrm{pFb}, 2 \mathrm{nd} \mathrm{pFb}$, and last $\mathrm{pFb}$ ). Single-trial data from correct trials preceded and were followed by a correct trial within a series when entered into the averages, except for the switch condition, in which participants occasionally needed a second trial to find the correct sorting rule. Finally, feedback-locked ERPs for incorrect trials were also computed for a subset of 15 participants for whom 15 or more artifact-free trials (ranging from 15 to 24) were obtained. For these negative feedback responses, only the 1st and 2nd negative feedback signals were averaged, which included the errors on switch trials and on the following trial after a switch error from all of the series. Distraction errors, which are errors that occur when a participant selects an incorrect category after having acquired the correct one earlier in the series, were not considered for the ERP analysis.

On the basis of previous WCST studies that employed ERPs, the analysis focused mainly on the P3 component (Barceló et al., 2002; Furumoto, 1991; Periañez et al., 2004; Stuss \& Picton, 1978; Watson et al., 2006). Time windows for the measurement of the P3 mean amplitudes were defined separately for cue and positive feedback events on the basis of the peak latencies of the P3 components located in the grand average at the Pz electrode. However, for both the first positive feedback (1st $\mathrm{pFb}$ ) and the switch cue, the peak latency of the P3 was located at $340 \mathrm{~ms}$ from the stimulus onset. Next, the mean amplitudes were determined within a \pm 50 -ms time window centered on these latencies. For the negative feedback $(\mathrm{nFb})$, mean amplitude was measured within a 200- to 300-ms time-window that encompassed the FRN, a specific component elicited by negative feedback. It has recently been shown that for an optimal signal-tonoise ratio that yields a stable FRN in a population of young healthy adults, a minimum of 20 epochs is recommended for averaging (Marco-Pallarès, Cucurell, Münte, Strien, \& Rodríguez-Fornells, 2011). However, due to the limitation of the total number of errors elicited in this task, we opted to reduce this criterion to a minimum of 15 epochs.

The mean amplitude values for cues were submitted to a repeated measures ANOVA with three within-subjects factors: trial type (four levels: switch vs. 1st Rep vs. 2nd Rep vs. last Rep), anterior-posterior (three levels: anterior [electrodes F3, Fz, and F4], central [C3, Cz, and $\mathrm{C} 4$ ], posterior [P3, Pz, and P4]), and laterality (three levels: left [electrodes F3, C3, and P3], middle [Fz, Cz, and Pz], and right [F4, C4, and P4]). Follow-up analyses were conducted to test specific comparisons made between the switch and repeat conditions. The mean amplitudes of the ERPs to feedback stimuli were submitted to (1) a three-way ANOVA with trial type (three levels: 1 st $\mathrm{pFb}$ vs. $2 \mathrm{nd} \mathrm{pFb}$ vs. last $\mathrm{pFb}$ ), anterior-posterior, and laterality as the withinsubjects factors and (2) an ANOVA with three withinsubjects factors, feedback type (two levels: $1 \mathrm{st} \mathrm{pFb}$ vs. $\mathrm{nFb}$ ), anterior-posterior, and laterality.

For all statistical effects involving two or more degrees of freedom in the numerator, the Greenhouse-Geisser epsilon was used to correct for possible violations of the sphericity assumption (Jennings \& Wood, 1976). The unadjusted degrees of freedom and adjusted $p$-values after the correction are reported. For illustrative purposes only, the grandaverage ERPs were filtered using a $12-\mathrm{Hz}$ low-pass filter.

Single-trial time frequency analysis

Data were analyzed offline using MATLAB (Mathworks, Natick, MA). Epochs comprised a 2,500-ms 
time window (625 sample points), including $900 \mathrm{~ms}$ prior to the stimulus onset. A continuous wavelet transformation on single-trial data for each participant and electrode was performed using a complex Morlet wavelet defined as follows:

$w(f, t)=\left(2 \pi \sigma_{t}^{2}\right)^{-1 / 2} e^{\frac{-t^{2}}{2 \sigma_{t}^{2}}} e^{2 i \pi f_{0} t}$,

where $f_{0} / \sigma_{f}$ (where $\sigma_{f}=1 /\left(2 \pi \sigma_{t}\right)$ ) was set at 7 (TallonBaudry, Bertrand, Delpuech, \& Permier, 1997). The time frequency representation of the signal $s(t)$, at trial $k$, frequency $f$, and time t was computed as follows:

$F_{k}(f, t)=w(t, f) \times s_{k}(t)$,

where $x$ denotes the complex convolution within a spectral band ranging from 3 to $45 \mathrm{~Hz}$ in one-by-one 42 -wavelet scales. For every time point and frequency bin, instantaneous power was computed by squaring of the convolution between the wavelet and signal. The long 2,500-ms time window was set to have a minimum of three cycles per frequency, thus allowing the assessment of low frequencies. Time frequency contents were then averaged for the trial type (i.e., switch vs. 1st Rep vs. 2 nd Rep vs. last Rep) and positive feedback (1st $\mathrm{pFb}$ vs. $2 \mathrm{nd} \mathrm{pFb}$ vs. last $\mathrm{pFb}$ ). Changes of spectral power (as a percentage) with respect to a baseline period from 200 to $50 \mathrm{~ms}$ were computed for each participant. The time frequency analysis was also performed for trials where a negative feedback was delivered. In parallel to the ERP analysis for this condition, the same subset of participants and trials was also included in the analysis.

To thoroughly study the specific band power effects at the different experimental conditions, we similarly analyzed the theta (4-6 Hz, 200-600 ms), alpha (8-12 Hz, 150-400 $\mathrm{ms})$, and beta-gamma $(20-30 \mathrm{~Hz}, 300-400 \mathrm{~ms})$ power change. Following the ERP analysis, we implemented a repeated measures ANOVA design, including trial type, anterior-posterior, and laterality, which contained the same electrodes previously defined in the ERP section. Cues, positive feedbacks, and positive and negative feedback comparisons were investigated by including the same levels within the trial type factor in the ANOVA. Separate ANOVAs were conducted for each frequency band. We also note that the theta band power was studied in a narrower frequency range than the "classical" 4-8 Hz referred to in other human studies. We were motivated to narrow the theta band to the lower frequency range because most of the effects across the experimental conditions seemed to be centered at this range and might help to homogenize our findings when they were compared across experimental conditions. The Greenhouse-Geisser epsilon was used when appropriate.

\section{Results}

Behavior

An average of $85.2 \%(S D=3.9)$ of correct trials (range, $75 \%-94 \%$ ) was observed. RTs (Fig. 1b) from valid series showed a robust task switch cost effect (main effect of trial type: $F(3,111)=53.6, p<.0001$; switch trial -1 st Rep trial $=317 \mathrm{~ms}$ ). Pairwise comparisons between the switch trials and all other trial types confirmed this effect ( $p<.0001$, for all comparisons). There was no significant difference between the 1st Rep and 2nd Rep trials $(p>.2)$, but a significant difference when the 2 nd Rep was compared against the last Rep $(p<.0001)$ was observed. However, the presence of differences in the RTs between the 1st Rep versus 2nd Rep versus last Rep trials revealed an asymptotic speedup of RTs across the series, $F(2,74)=$ $16.9, p<.0001$ (Fig. 1b).

The error analysis for failed series confirmed the presence of an accuracy task switch cost (main effect of trial type: $F(2,74)=69.5, p<.0001)$. Thus, participants were more prone to errors after switch trials (i.e., trial 2) than after trial 3 and last trials from the series $(p<.0001$; switch cost, switch trial -1 st Rep trial: 3 errors). In addition, fewer errors were observed for the 2nd Rep than for the last Rep trials $(p<.0001$; see Fig. 1c).

\section{ERPs}

Cues The electrophysiological responses for the switch and repeat cues are shown in Fig. 2a, b. A clear P3 component was evoked by the switch cue [trial type, $F(3,111)=95.6$, $p<.0001$; cue switch vs. 1st Rep: $F(1,37)=115.6, p<$ .0001 ; see Fig. 2a), but not for subsequent repeat cues [trial type (1st Rep vs. 2 nd Rep vs. last Rep), $F(2,74)<1, p>.7$; trial type $\times$ anterior-posterior and trial type $\times$ laterality, $F<$ 1; see Fig. 2b]. The scalp distribution of this P3 component was posterior [Fig. 2a; trial type $\times$ anterior-posterior, $F(6$, $222)=63.0, p<.0001]$, with a maximum on the middleposterior side [trial type $\times$ laterality, $F(6,222)=23.8, p<$ .0001 ; trial type anterior-posterior $\times$ laterality, $F(12,444)=$ $5.6, p<.0001]$.

Feedback ERPs elicited by the correct feedback stimuli are shown in Fig. 2c. Interestingly, the first positive feedback event from a series $(1 \mathrm{st} \mathrm{pFb})$ elicited a robust $\mathrm{P} 3$ [trial- ype: $F(2,74)=164.5, p<.0001]$ that dramatically decreased in amplitude for subsequent positive feedback events $[1 \mathrm{st} \mathrm{pFb}$ vs. 2 nd $\mathrm{pFb}, F(1,37)=184.7, p<.0001 ; 1 \mathrm{st} \mathrm{pFb}$ vs. last $\mathrm{pFb}, F(1,37)=202.6, p<.0001]$, even though the $\mathrm{P} 3$ for the $2 \mathrm{nd} \mathrm{pFb}$ was larger than for the last $\mathrm{pFb}$ of the series, $F$ $(1,37)=4.5, p<.05$. This component had a posterior maximum [trial type $\times$ anterior-posterior: $F(4,148)=12.5$, 


\section{CUES}

A.
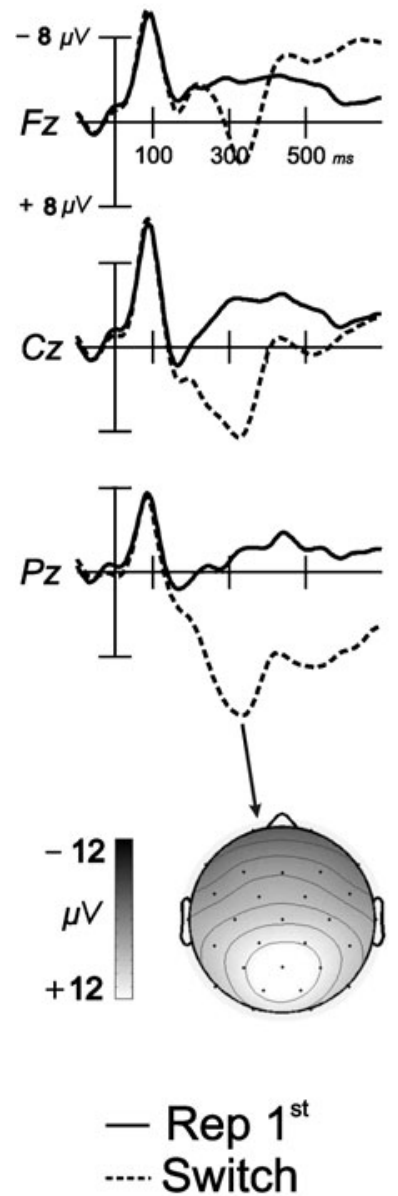

B.
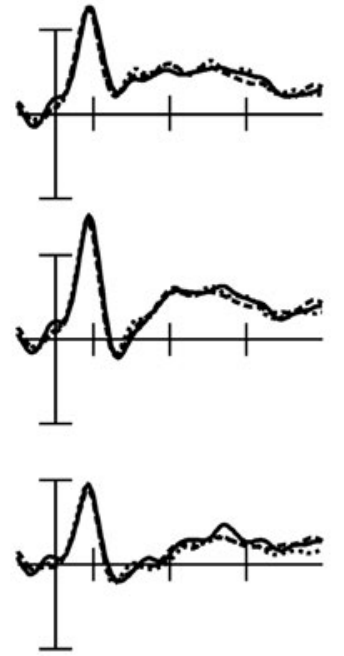

Fig. 2 a Grand average ERPs for switch and 1st Rep cues at midline electrode locations ( $\mathrm{Fz}, \mathrm{Cz}$, and $\mathrm{Pz}$ ). A large P3 component with two consecutive peaks (early and late $\mathrm{P} 3$ ) is elicited by the switch cue that indicates that the participant should change the current classificatory rule. Isovoltage mapping with spherical spline interpolation depicts the scalp distribution of the early and late P3 components (peak latency at Pz: 340 and $516 \mathrm{~ms}$ ). b A very similar morphology of the ERP waveforms is observed for the consecutive repeat cues (1st Rep, 2nd Rep, and last Rep); note the absence of the P3 component for repeat trials. c Grand average ERPs showing the electrophysiological responses at the midline electrode array $(\mathrm{Fz}, \mathrm{Cz}$, and $\mathrm{Pz})$ to first,

$p<.0001]$, with a maximum located on the middleposterior side [trial type $\times$ laterality, $F(4,148)=17.8, p<$ .0001 ; trial type $\times$ anterior-posterior $\times$ laterality, $F(8$, $296)=5.6, p<.0001]$, similar to the auditory P3 elicited by the switch cues, as illustrated by the isovoltage map in Fig. 2c.

Figure $2 \mathrm{~d}$ depicts the ERPs for positive $(1 \mathrm{st} \mathrm{pFb})$ and negative $(\mathrm{nFb})$ responses. A clear FRN was obtained in response to negative feedback signals, with a maximum at around $280 \mathrm{~ms}$ and a typical mid-central distribution. This observation was corroborated by a significant main effect of

\section{FEEDBACK}
C.
D.
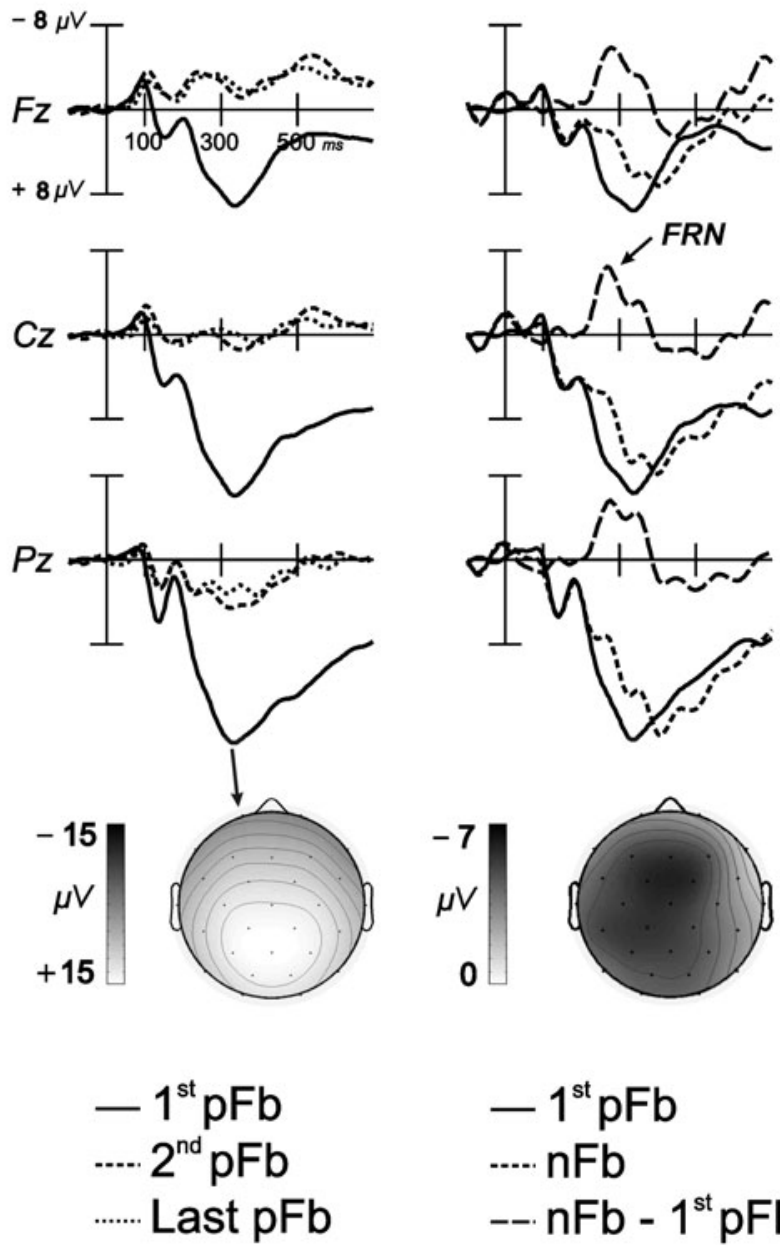

$-1^{\text {st }} \mathrm{pFb}$

..... $\mathrm{nFb}$

-- $\mathrm{nFb}-1^{\text {st }} \mathrm{pFB}$

second, and last visual positive feedback stimuli. A clear P3-like component $(\sim 15 \mu \mathrm{V})$ with a centro-parietal distribution is observed for the first positive feedback (see isovoltage map below). d Electrophysiological signature for positive (first) and negative (first and second) feedback stimuli in a series at the midline electrode array $(\mathrm{Fz}, \mathrm{Cz}$, and $\mathrm{Pz}$ ) for a subset of 15 participants for whom 15 or more errors (epochs free of artifacts) on the first trials of a new series were recorded. A clear feedback related negativity (FRN) with a mid-central distribution (see isovoltage map below) is observed at the 200- to $300-\mathrm{ms}$ time range (peak around $280 \mathrm{~ms}$ ) when subtracting positive from negative feedback events

feedback type, $F(1,14)=12.0, p<.01$, and a nonsignificant interaction between trial type and laterality, $F(2$, $28)=2.2, p>.1$, and between trial type and anteriorposterior, $F<1$.

Time frequency analysis

Cues The TF results are depicted in Figs. 3a, b, and 4a. Details of the repeated measures ANOVA are reported in 


\section{A.Cues}
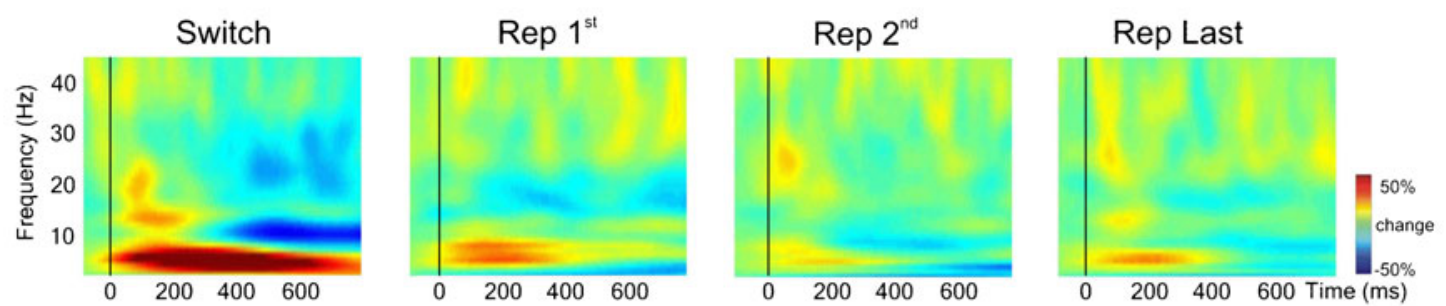

B.

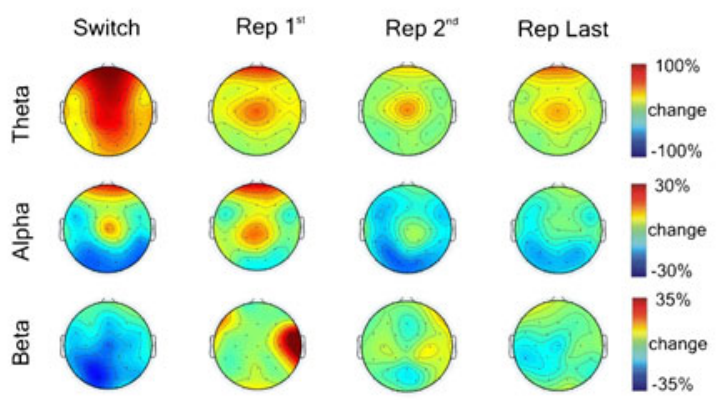

\section{Feedback}
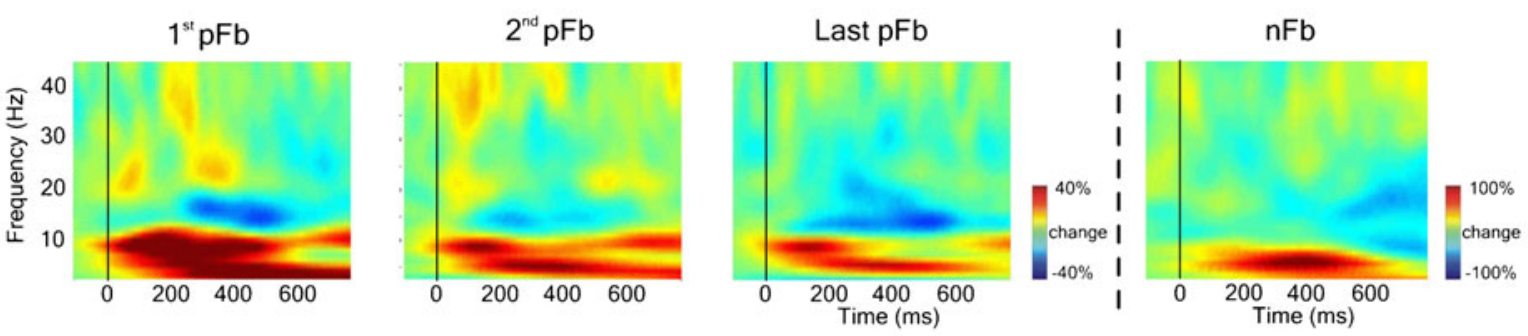

D.

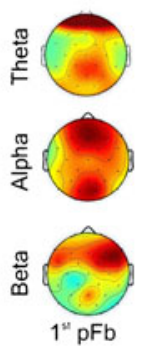

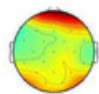
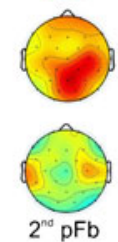

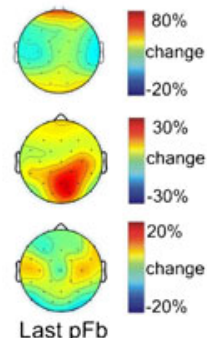

\section{E.}

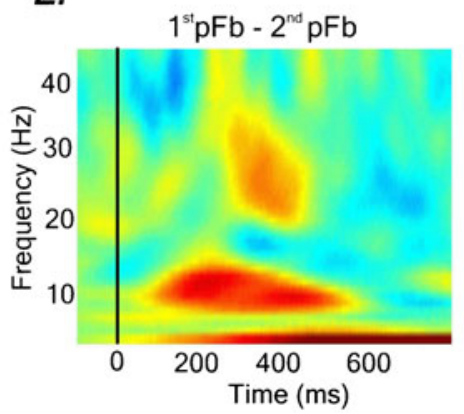

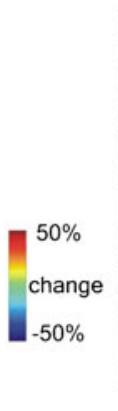

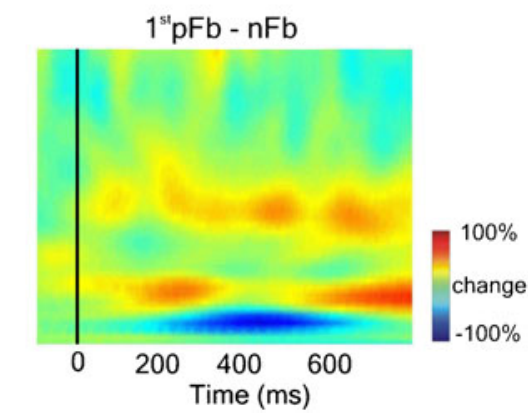

Fig. 3 a Grand average spectral power modulations for switch and repeat cues at $\mathrm{Fz}$ electrode. b A clear theta band $(4-6 \mathrm{~Hz})$ enhancement due to the switch cue was observed at frontal, central, and parietal regions, which disappeared after consecutive repeat cues (time window, 200-600 ms). c Grand average spectral power modulations at $\mathrm{Fz}$ electrode after all positive feedback stimuli (1st $\mathrm{pFb}, 2 \mathrm{nd} \mathrm{pFb}$, and last $\mathrm{pFb}$ ) and negative feedback (nFb). Note the

Table 1. Henceforth, the results in this section will be indicated on the basis of the ANOVA significant effects, and we will refer the reader to Table 1 to observe the $F$ values. Theta power increase was observed for the switch and showed a marked decrease for all the repeat cues (the main effect of trial type; linear trend, $F(1,37)=21.9, p<$ increase in theta, alpha, and beta after the $1 \mathrm{st} \mathrm{pFb}$. d Topographical map of the mean theta $(4-6 \mathrm{~Hz}, 200-600 \mathrm{~ms})$, alpha $(8-12 \mathrm{~Hz}, 150$ $400 \mathrm{~ms}$ ), and beta $(20-30 \mathrm{~Hz}, 300-400 \mathrm{~ms})$ band components during positive feedback responses. e At Fz location, comparison of mean spectral power differences for first over second positive feedback and first positive feedback over negative feedback $(\mathrm{nFb})$

.001 ; quadratic trend, $F(1,37)=117.9, p<.001$; see Fig. $4 a)$. Theta enhancement was mostly represented at frontal and medial posterior regions (Table 1, Figs. 3a, b, and 4a). However, theta power effects at frontal and central scalp regions behaved differently for repeated cues. While theta at the frontal regions was absent after repeated cues, theta at 


\section{A. Cues}
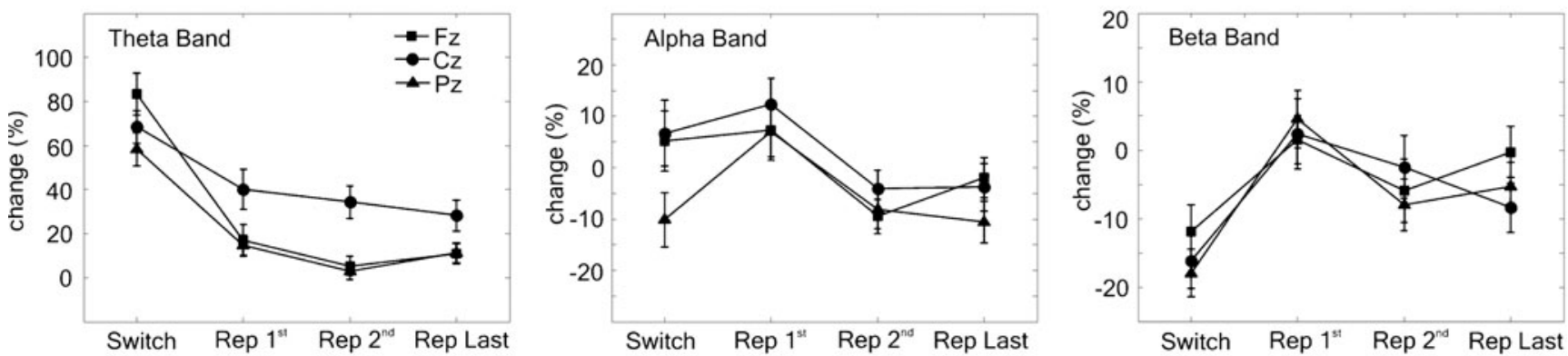

\section{B. Feedback}
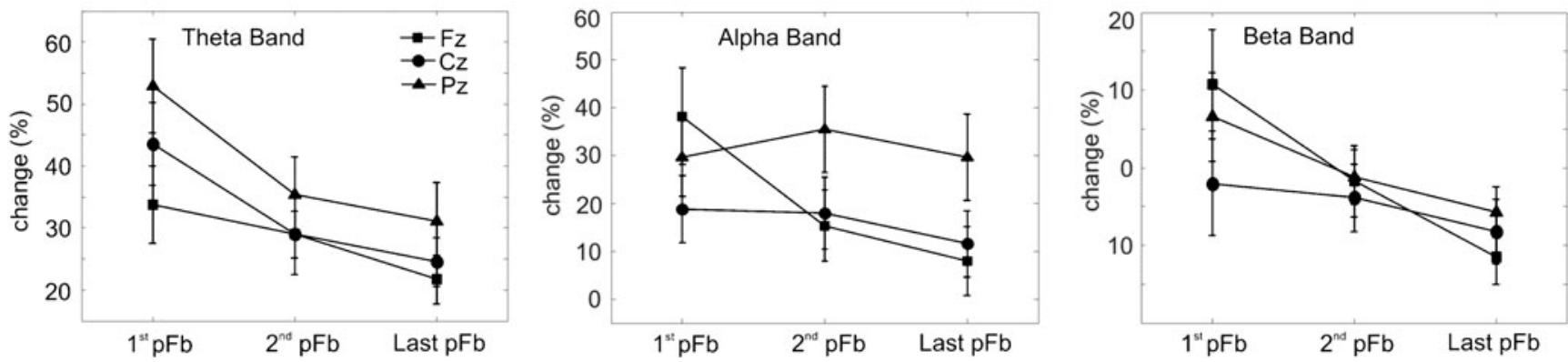

Fig. 4 a Mean power changes for, from left to right, theta $(4-6 \mathrm{~Hz}$, 200-600 ms), alpha (8-12 Hz, 150-400 ms), and beta $(20-30 \mathrm{~Hz}$, $300-400 \mathrm{~ms}$ ) frequency bands at $\mathrm{Fz}, \mathrm{Cz}$, and $\mathrm{Pz}$ electrodes after all switch and repeat cues. b Mean power changes for, from left to right,

theta (4-6 Hz, 200-600 ms), alpha (8-12 Hz, 150-400 ms), and beta (20-30 Hz, 300-400 ms) frequency bands at Fz, Cz, and Pz electrodes after all positive feedback stimuli. Error bars indicate standard errors of the means

the frontal regions was still observable at the 1 st repeat cue (type $\times$ anterior-posterior effect; Fig. 4a). The averaged theta power at the frontal (F3,Fz, F4), central (C3, Cz, C4) and parietal $(\mathrm{P} 3, \mathrm{Pz}, \mathrm{P} 4)$ regions was included in a followup post hoc repeated measures ANOVA. The results of these analyses (see details in Table 2) confirmed that the dissociation of the theta effect observed between the frontal and central components disappeared when the ANOVA was calculated from each scalp location separately.

Furthermore, with respect to the previous results in Sauseng et al. (2006), the switch cues elicited an expected decrease in the alpha band at centro-posterior and occipital regions, which was not observed for the remaining repeat cues (Fig. 3a; see also the topographical maps of the alpha decrease in Fig. 3b). A beta-gamma band power decrease was also elicited when the switch cues were delivered (trial type effect), but not after cue repetition (trial type effect, linear trend: $F(1,37)=9.59, p<.01)$. No differences were observed for the decrease in the beta-gamma band, which suggests a generalized effect across the scalp, although this effect seems to be more pronounced in the posterioroccipital regions (see Fig. $3 \mathrm{~b}$ for the topographical representation of this beta-gamma decrease effect).

To further compare the information from the ERP and the time frequency analyses, we separately correlated, for each cue stimulus at $\mathrm{Fz}, \mathrm{Cz}$, and $\mathrm{Pz}$, the magnitude of the
P3 (mean amplitude at the time window $\pm 50 \mathrm{~ms}$ around the peak) with the average power from theta, alpha, and betagamma bands. Specific band power was obtained from averaging theta $(4-6 \mathrm{~Hz})$ power from 200 to $600 \mathrm{~ms}$, alpha $(8-12 \mathrm{~Hz})$ power from 150 to $400 \mathrm{~ms}$, and beta-gamma $(20-30 \mathrm{~Hz}$ ) power from 300 to $400 \mathrm{~ms}$ (i.e., values similar to those used in the ANOVA for the TF effects). The results of these correlation analyses revealed a positive significant correlation only between the P3 amplitude and the power for the theta band at Fz electrode for switch cues $(r=.41, p$ $<.01$ ), while nonsignificant correlations were found between the P3 and alpha or beta-gamma power changes at the remaining electrodes and between the rest of the cue stimuli (all $p \mathrm{~s}>.05$ ).

In sum, the switch cues induced an increase in the theta oscillatory power at frontal-midline locations and a suppression of the alpha and beta-gamma power, specifically at the posterior-occipital sides.

Feedback As in the previous section, the specific band power effects are described here according to the ANOVA results detailed in Table 1, to which we refer the reader for completeness. Figures $3 \mathrm{c}$, e, and $4 \mathrm{~b}$ depict the spectral power modulations following positive feedback in which a clear increase of theta, alpha and betagamma band power was observed in response to the 1 st, as 


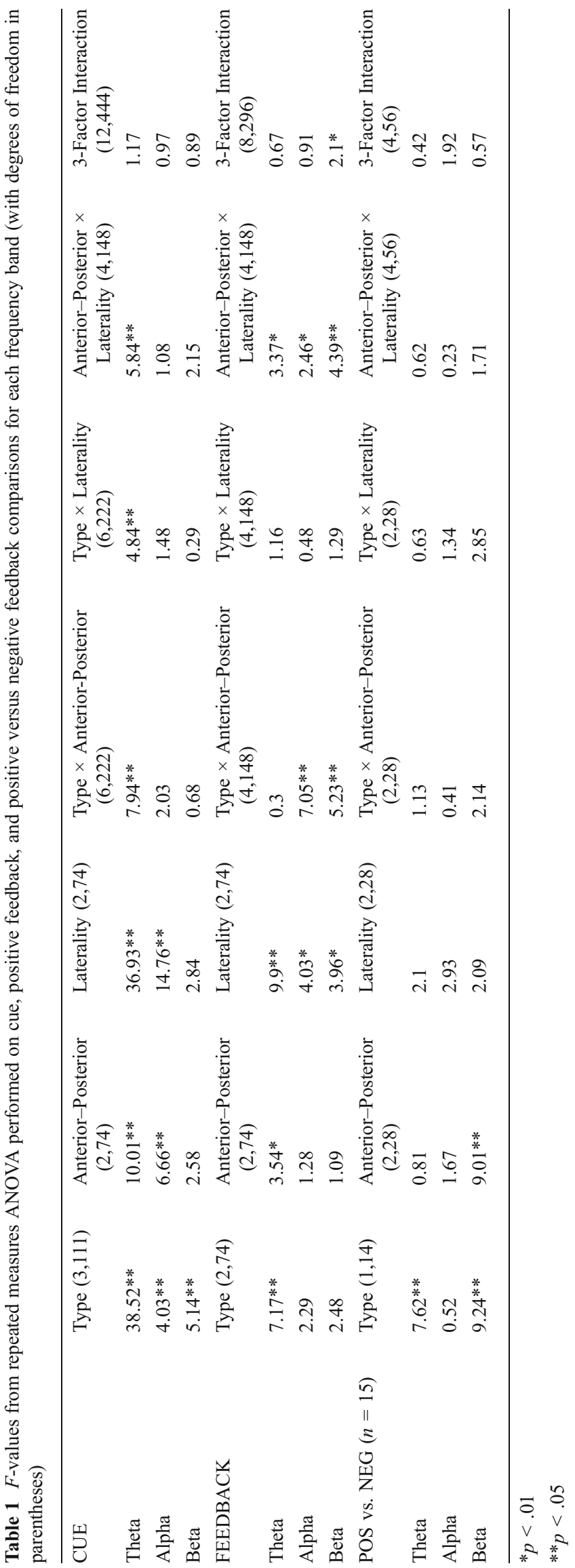

compared with 2nd and last positive feedback. Statistical analyses revealed clear differences between feedback trials in the theta band (trial type effect). Theta appeared dominant over the frontal and central regions and slightly right lateralized (anterior-posterior effect and laterality effect) and showed a marked decreased with the 2 nd positive and last positive feedback [trial type, linear trend: $F(1,37)=6.41, p<.01]$. Follow-up pairwise comparisons at frontal (averaged F3, Fz, and F4), central (averaged C3, $\mathrm{Cz}$, and $\mathrm{C} 4$ ), and parietal (averaged $\mathrm{P} 3, \mathrm{Pz}$, and $\mathrm{P} 4$ ) components revealed that the theta increase was most prominent after the 1st positive feedback at the central and parietal scalp regions (see Table 2). No significant differences were found between 2 nd and last positive feedback (in all cases, $F<1$ ), although a statistically significant linear trend demonstrated a gradual reduction of feedbackrelated theta activity along the trials of a given series $[F(1$, $37)=4.25, p<.05$; quadratic trend, $F(1,37)=0.49, p>$ .1; see Fig. 4b]. Positive feedback responses also showed an unexpected enhancement of the alpha band power (150-400 ms stimulus onset) that was not found in previous studies that reported EEG spectral power changes to feedback processing (Marco-Pallarès et al., 2008; Marco-Pallarès et al., 2009). The significant interaction of trial type and anterior-posterior (Figs. 3c, d, and 4b) reflected the fact that, at the parietal scalp regions, the enhancement of the alpha band power was similar for the different trials, whereas at frontal locations, alpha increase was present only for the 1 st positive feedback (see Figs. $3 \mathrm{~d}$ and $4 \mathrm{~b}$ and Table 1). Furthermore, a modulation of frontal beta-gamma band power was observed mostly for the 1 st positive feedback [see Figs. 3c-e and $4 \mathrm{~b}$; trial type $\times$ anterior-posterior: linear trend, $F(1$, $37)=12.05, p<0.01$; quadratic trend, $F(1,37)=6.92, p$ $<.01]$, with a slight lateralization over the right hemisphere (anterior-posterior $\times$ laterality effect). Differences between 1st and 2nd feedbacks are depicted in Fig. 3e. Pairwise comparisons indicated that the frontal beta-gamma enhancement was present only after the 1 st positive feedback (Fig. 4b and Table 2).

The study of the specific band power effects to positive and negative feedback responses are also detailed in Table 1. The ANOVA showed that while theta power was enhanced following negative feedback delivery (feedback type effect), a power increment in the range of the beta-gamma band was observed after positive feedback display (feedback type effect) (see Fig. 3c-e). This beta-gamma band effect was more pronounced over frontal regions (anteriorposterior effect) (Fig. 3c-e). No differences were found at the range of the alpha band (Fig. 3c, d).

Finally, as performed for the cue condition and as described by Cohen et al. (2007), we conducted a correlation analysis for feedback conditions to compare 
Table $2 F$-values from post hoc ANOVA performed on cue and positive feedback comparisons for each frequency band (with degrees of freedom in parentheses)

\begin{tabular}{|c|c|c|c|c|c|c|}
\hline \multirow[t]{2}{*}{ CUE } & \multicolumn{3}{|c|}{ Switch vs. 1st Rep $(1,37)$} & \multicolumn{3}{|c|}{ Switch vs. 1st Rep vs. Last Rep $(2,72)$} \\
\hline & Theta & Alpha & Beta & Theta & Alpha & Beta \\
\hline Frontal & $33.14 * *$ & 0.14 & $6.15^{*}$ & $34.91 * *$ & 1.79 & $3.69 *$ \\
\hline Central & $21.69 * *$ & 1.17 & $5.93 *$ & $28.63 * *$ & 1.33 & $3.91^{*}$ \\
\hline Parietal & $12.54 * *$ & 3.05 & $14.25 * *$ & $11.19 * *$ & $3.16^{*}$ & $5.56^{* *}$ \\
\hline \multirow[t]{2}{*}{ POSITIVE FEEDBACK } & Theta $(1,37)$ & & Alpha $(1,37)$ & & Beta $(1,37)$ & \\
\hline & 1st vs. 2nd & 1st vs. Last & 1st vs. 2nd & 1st vs. Last & 1st vs. 2nd & 1st vs. Last \\
\hline Frontal & 0.77 & 2.79 & 4.08 & $14.61 * *$ & $4.73 *$ & $11.52 * *$ \\
\hline Central & $5.72 *$ & $10.43 * *$ & 0.19 & $4.35^{*}$ & 0.25 & 1.26 \\
\hline Parietal & $9.3^{* *}$ & $7.18^{*}$ & 1.57 & 0.12 & 0.27 & 0.01 \\
\hline
\end{tabular}

"Frontal" represents the averaged power activity of F3, Fz, and F4 electrodes. "Central" represents the averaged power activity of $\mathrm{C} 3, \mathrm{Cz}$, and $\mathrm{C} 4$ electrodes. "Parietal" represents the averaged power activity of $\mathrm{P} 3, \mathrm{Pz}$, and $\mathrm{P} 4$ electrodes.

$* p<.05$

$* * p<.01$

the information provided by the FRN and specific band power effects. In agreement with the results of Cohen et al. (2007), we found a significant positive correlation between the FRN amplitude (negative minus positive feedback) and the difference between negative and positive feedback responses at the theta band $(\mathrm{Cz}$ electrode; $r=.51, p=$ $.05)$. Therefore, the greater the amplitude of the FRN (negative in polarity), the higher the difference in theta power. Power changes of the alpha and beta-gamma bands did not correlate with the FRN amplitude at any other electrode (all $p \mathrm{~s}>.05$ ). Similarly, no correlations between the positive feedback-related P3 amplitude and theta power reached statistically significant values at any electrode location (all $p \mathrm{~s}>.05$ ).

\section{Discussion}

The present EEG study was designed to dissociate the neural events associated with environmental signals indicating feedback about performance (outcome-based behavioral adjustment) and signals indicating the need to switch or repeat task sets (rule-based behavioral adjustment). Our ERP results showed, on the one hand, the existence of common neural P3 responses to signals indicating the need to update current behavioral task rules, as well as to feedback signals (Fig. 2). On the other hand, negative feedback elicited an FRN, which is an ERP component that has been specifically associated with negative outcomes (e.g., monetary losses) (Gehring \& Willoughby, 2004; Holroyd \& Coles, 2002). With respect to previous findings (Cohen et al., 2007; Marco-Pallarès et al., 2008; MarcoPallarès et al., 2009; van de Vijver et al., in press; Haji Hosseini et al., 2011), positive feedback elicited a modulation in the beta-gamma band that was observed neither for switch nor for repetition cues (Cohen et al., 2007; Marco-Pallarès et al., 2008; Marco-Pallarès et al., 2009). Furthermore, the time frequency analysis showed an abrupt decrease for the theta power from switch to repeat cue signals, whereas the feedback-related theta exhibited a gradual decrease across consecutive positive feedback signals (Figs. 3 and 4). Finally, and as would be expected considering the results of previous studies (see Sauseng et al., 2006), switch cues showed a suppression of alpha and beta oscillatory bands at posterior-occipital locations. In sum, the complementary ERP and time frequency results provide support for the distinction between the neurocognitive mechanisms underlying these two forms of behavioral adjustment and outcome-based and rule-based behavioral adjustments.

Common theta activity to cue and feedback signals in cognitive control processes

$\mathrm{TF}$ analysis showed power modulations of theta, alpha, and beta-gamma frequency bands in the different WCST phases. In particular, a common frontocentral increase of the theta band power was observed in those cue and feedback trials showing analogous P3-like responses (i.e., switch vs. $1 \mathrm{st} \mathrm{pFb}$ trials). Thus, theta activity in response to switch cues was no longer observed for consecutive repeat cues. However, there was a gradual reduction of the theta band activity in response to the consecutive $1 \mathrm{st} \mathrm{pFb}, 2 \mathrm{nd}$ $\mathrm{pFb}$, and last $\mathrm{pFb}$ stimuli as indicated by the observed significant linear trend effect (Figs. 3, 4).

The theta activity effect detected after the switch and the 1st positive feedback was also found at more anterior parts of the frontal regions. Similarly, the frontopolar theta activity has been previously observed in association with target detection (Delorme, Westerfield, \& Makeig, 2007; 
Makeig et al., 2004; Makeig et al., 1999; Potts \& Tucker, 2001). These studies showed that attentional or motivational salient stimuli triggered a frontal component appearing earlier than P3b (referred to as P3f in the cited studies), which is mainly accounted for by the low-theta oscillatory activity (Delorme et al., 2007; Makeig et al., 2004). Thus, our findings showed a similar frontopolar theta component appearing after the switch and $1 \mathrm{st} \mathrm{pFb}$ signals that may point out potential common neural processes taking place when participants detect salient or relevant stimuli during the task.

Importantly, similar frontocentral theta band power increases have previously been shown to be associated with negative feedback signals and error responses (Cavanagh et al., 2009; Luu, Tucker, \& Makeig, 2004; Yordanova, Falkenstein, Hohnsbein, \& Kolev, 2004), monetary losses (Cohen et al., 2007; Gehring \& Willoughby, 2004; MarcoPallarès et al., 2008), task-switching cues (Sauseng et al., 2006), and the maintenance of items in working memory (Gevins, Smith, McEvoy, \& Yu, 1997; Sarnthein, Petsche, Rappelsberger, Shaw, \& von Stein, 1998). Although it still needs to be shown whether these theta modulations reflect analogous cognitive and neural mechanisms, at least partially common mechanisms can be inferred. In general, increases in the theta band seem to be relevant for indexing undesirable or negative outcomes and when further adjustments in the behavior are requested for learning or to improve the performance on subsequent trials (van de Vijver et al., in press; Womelsdorf, Johnston, Vinck, \& Everling, 2010). One possibility is that some of these experimental paradigms and, in particular, switch cues and positive feedback signals from our modified WCST engage analogous cognitive control mechanisms reflected in the theta response. Accordingly, the frontal midline theta oscillatory activity in response to both cue and feedback signals of the WCST may reflect the broad coordination of several brain regions to increase top-down control for monitoring conflict between alternative task sets, both when a new task set has to be activated in memory (i.e., following switch cues) and when the recently activated task set needs to be maintained (i.e., following feedback events).

In this regard, interference theories have proposed that task switch costs are substantially or wholly attributable to conflict arising from a memory mismatch between internal and external information (Badre \& Wagner, 2006; Gilbert \& Shallice, 2002; Yeung \& Monsell, 2003). Accordingly, the switch-related theta band modulation may indicate cognitive control to overcome the conflict between alternative and competing task sets. This interpretation is consistent with functional neuroimaging studies revealing activation in a frontal network devoted to conflict monitoring consisting of the anterior cingulate cortex and dorsolateral prefrontal cortex (Badre \& Wagner, 2006; Luks, Simpson,
Feiwell, \& Miller, 2002; Monchi et al., 2001; Periañez et al., 2004; van Veen \& Carter, 2002). This explanation would account for the lack of a similar power increase after repeat cues, since no conflict exists regarding which task set should be activated. In terms of task switching, the abrupt reduction of the theta activity observed for repeat cues would indicate that a task set reconfiguration process, triggered by the switch cue, has been effectively completed and that this process does not need to be engaged again while the task remains unchanged - that is, on the subsequent repeat trials (Meiran, 1996; Rogers \& Monsell, 1995).

All of these interpretations of the theta band modulation fit well with models of executive function arguing that the prefrontal cortex acts as a top-down attentional controller, biasing competition and modulating the information processing in posterior regions on the basis of current goals or plans (Miller \& Cohen, 2001; Passingham, 1993; Shallice, 1988). Previous results have suggested that executive control is necessary in the early phases of trial-and-error learning, during which competing cognitive schemas and alternative behaviors may interfere with accurate performance (Holroyd \& Coles, 2002; Luu, Shane, Pratt, \& Tucker, 2009). In the present experiment, positive feedback events evoked a frontal midline theta band activity nearly similar to the one described for switch cues. In this case, however, a gradual power decrease was observed to follow consecutive positive feedback events. Interestingly, in previous studies using simple feedbacks indexing monetary gains in gambling tasks, the increase in theta power was not observed (see, e.g., Marco-Pallarès et al., 2008).

As was stated before, theta increases are usually observed after the negative monetary feedback or for incorrect trials, as was also the case in the present study for the negative feedback trials (see Fig. 3e). Thus, the first feedback after a correct switch showed an overlap in the oscillatory components, exhibiting the beta-gamma oscillatory component associated with positive monetary gains and an increase in the theta associated with cognitive control operations. This increase in theta and its gradual decline, as compared with the theta-elicited increase in switch cues, might represent the existence of residual conflict-monitoring and control operations that come into play to firmly establish the task set following positive feedback. In this sense, the increase in theta power following the first correct feedback may indicate that some of the cognitive operations involved in the process of task reconfiguration are accomplished with the processing of feedback (Monsell, 2003; Rogers \& Monsell, 1995).

The role of feedback in cognitive control

An increase of a frontal beta-gamma band activity was observed after the first positive feedback stimulus, which 
was reduced for consecutive positive feedback events (Figs. 3d and $4 \mathrm{~b}$ ). Importantly, this frontal beta-gamma increase was specific to feedback stimuli and was not observed after cue stimuli, since it was reduced across the scalp after the switch cue. This clear dissociation between the cue and feedback stimuli emphasizes our initial assumption that conventional ERP analysis may be partially blind to differences in brain activity related to these different phases of the WCST. In previous EEG studies, an increase of this frontal beta-gamma activity was found for positive rewarding events in gambling tasks (Marco-Pallarès et al., 2008; Marco-Pallarès et al., 2009; for a recent replication using MEG, see Bunzeck, Guitart-Masip, Dolan, \& Düzel, 2011; Doñamayor, Marco-Pallarès, Heldmann, Schoenfeld, \& Münte, in press) but also in probabilistic reinforcement learning tasks (Cohen et al., 2007; but see Cavanagh et al., 2010). In addition, a recent study showed that this response was specific for unexpected positive feedbacks in a gambling task (see also Cohen et al., 2007) and that it predicts the amount of learning after the appearance of positive and negative feedbacks (van de Vijver et al., in press; Haji Hosseini et al., 2011).

The beta-gamma component was initially interpreted by Marco-Pallarès et al. (2008) as a possible reinforcement learning neural signature of reward that is involved in the synchronization of neural regions over long distances to couple frontal and striatal structures involved in reward processing. This would be consistent with earlier proposals that beta-gamma oscillations are suited for the functional coupling of distributed brain regions (Berns, McClure, Pagnoni, \& Montague, 2001; Steriade, 2006). It has been proposed that frequency coherence in the beta and gamma band between distant structures can act as a mechanism for large-scale integration (Varela, Lachaux, Rodriguez, \& Martinerie, 2001). However, the exact neural mechanisms generating the increase of the beta-gamma band power after positive and confirmatory feedbacks remain to be fully understood. Using intracranial recordings in animals, an increased beta and gamma oscillatory activity at the striatum and frontal cortex after rewarded actions has been shown (Berke, 2009; Courtemanche, Fujii, \& Graybiel, 2003; Kalenscher, Lansink, Lankelma, \& Pennartz, 2010; van der Meer \& Redish, 2010). In humans, an increase in the cortical EEG beta-gamma power has also been observed in response to the delivery of reward (Hallschmid, Molle, Fischer, \& Born, 2002). Importantly, the response properties of distinct reward-related networks have been associated with transient (prefrontal cortex) and sustained (ventral striatum) dopaminergic activities (Dreher, Kohn, \& Berman, 2006). On the basis of these results, it has been suggested that the beta-gamma band response might reflect the orchestration of the different reward and emotionrelated structures within the frontostriatal circuits necessary for monitoring performance and selecting actions (Càmara, Rodríguez-Fornells, \& Münte, 2010; Càmara, RodríguezFornells, Ye, \& Münte, 2009). The frontocentral topography of the beta-gamma component observed in the present study for positive feedbacks is compatible with the ventromedial prefrontal activations reported in studies on reward and punishment processing (Kim, Shimojo, \& O’Doherty, 2006; Knutson, Fong, Bennett, Adams, \& Hommer, 2003; Nieuwenhuis, Slagter, von Geusau, Heslenfeld, \& Holroyd, 2005; Tom, Fox, Trepel, \& Poldrack, 2007). A follow-up study has also suggested the possible dopaminergic origin of the beta-gamma activity (Marco-Pallarès et al., 2009), in convergence with recent studies showing that changes in dopamine levels are associated with the reestablishment of gamma band oscillations and a change from low- to high-oscillatory activity (Brown et al., 2001; Lalo et al., 2008).

However, in light of the studies reported by Haji Hosseini et al., (2011) and van de Vijver et al. (in press), together with this present work, in which the beta-gamma increase was selective for the first positive feedback, we believe that this component reflects a brain signature associated with the processing of relevant and novel positive information that is required for learning purposes or for general future behavioral adjustments. In this particular case, for example, it might reflect the strengthening of the new task set correctly chosen among the different alternatives. This idea converges with the findings of Axmacher et al. (2010), who showed a large increase in the gamma activity in the ventral striatum (nucleus accumbens) in response to unexpected events that had to be encoded in long-term memory. Thus, the beta-gamma increase observed in the present study could represent a brain signature that might respond to unexpected positive outcomes by transmitting a fast motivational value signal to downstream brain reward-related structures. In our WCST task, the interpretation of the increase in beta activity was partially associated with the reinforcement of the correctly chosen task set and is compatible with the recent proposal of Engel and Fries (2010) regarding the role of beta band oscillations. These authors have suggested that the beta band oscillations index the tendency of the sensorimotor system to maintain its "status quo" (Engel \& Fries, 2010). A prediction from this theory is that the beta activation might be related to a more efficient processing of the feedback signals that are needed for monitoring the status quo and recalibrating the sensorimotor system (Baker, 2007). Therefore, in the present context, the beta-gamma signal will be associated with an endogenous cognitive control process with the aim of reinforcing the maintenance of the new selected rule; in this manner, the efficiency of the processing in the next trials is increased, and attentional distractions or incorrect switches are avoided. 
The involvement of a general feedback learning or error prediction system in the current version of the WCST is further supported by the observation of the FRN component in the ERP analysis, which is typically elicited by negative feedback and punishment signals. The FRN has been studied extensively in the context of learning (Eppinger, Kray, Mock, \& Mecklinger, 2008; Holroyd \& Coles, 2002; Müller et al., 2005; Nieuwenhuis et al., 2002), using either probabilistic or associative learning tasks. In such tasks, the appearance of an FRN is related to the information transmitted by the negative feedback signal. Indeed, the FRN is commonly observed accompanying outcomes that are worse than expected (Gehring \& Willoughby, 2004), and its amplitude has been found to correlate positively with the negative prediction error of reinforcement learning models (Chase, Swainson, Durham, Benham, \& Cools, 2011).

The present findings could be explained by considering the idea that feedback-related EEG components like the FRN represent a rapid assessment of the motivational impact in terms of a good-bad dichotomy (Gehring \& Willoughby, 2004), as sustained by the dopaminergic system. In our task, the feedback is motivationally relevant as long as it provides important information (either positive or negative) for the goal-directed behavior in the subsequent trial that occurs when we observed feedback-specific EEG effects. This hypothesis is supported by the recent finding from Savine and Braver (2010), who showed the close relationship that exists between reward and cognitive control processes in a task-switching experiment (see also Kouneiher, Charron, \& Koechlin, 2009). The authors reported a direct motivational influence in both brain activity and behavioral improvement related to cognitive control, providing evidence that motivational incentives can induce an enhancement in cognitive control that is reflected in behavioral improvement (a reduced switch cost).

Different processing phases of task switching differentially modulate late P3 ERP responses

Conventional ERP analysis has been used in the past to clarify the functional relationship between behavioral effects and the cognitive operations that take place during the distinct processing phases in the WCST (Barceló et al., 2002; Furumoto, 1991; Kopp et al., 2006; Stuss \& Picton, 1978; Watson et al., 2006). The present cue-locked ERP results replicate findings that establish a functional relationship between the behavioral switch costs and the amplitude enhancement of a frontoparietally distributed cue-locked P3 component in tasks similar to the WCST (Barceló et al., 2002; Kopp et al., 2006) and other taskswitching paradigms (Hsieh \& Liu, 2005; Nicholson et al., 2005; Rushworth et al., 2002). Both the presence of a larger switch P3 effect (in response to switch cues in a WCST-like paradigm, which uses an equally probable switch and repeat cue; Periañez \& Barceló, 2009) and a large reduction of cue-locked P3s (when the same sequence of stimuli was applied under oddball, as compared with task-switching, instructions; Barceló, Periañez, \& Nyhus, 2007) have previously suggested that cue-locked task-switching P3 effects cannot be accounted for in terms of a simple oddball effect. In this regard, these long latency P3 responses have been generally interpreted as genuine neural correlates of a preparatory top-down reconfiguration mechanism for task switching. In contrast to previous studies that have reported a residual P3 cue-locked activation in response to the first repeat cue (Barceló et al., 2002), we found that cue-locked P3 activity in 1st Rep trials completely disappeared and showed no changes across consecutive repetition trials (Fig. 2a, b). This finding, therefore, might be driven by the appearance of the positive feedback signal after the first correct response to a switch cue. In previous WCST paradigms, participants needed at least two cues to confirm the correctness of the response choice. This was not the case here, because a positive feedback after the first correct choice explicitly informed participants about the correctness of the new choice and signaled that they should maintain the updated rule on the subsequent trial. Accordingly, this rules out the presence of task-switching mechanisms for the repeat cues that would consequently be reflected by the disappearance of the P3 component. This argument is further supported by the emergence of a robust P3 component to the first positive feedback event in a trial series that was dramatically reduced for subsequent feedback events. In a similar vein, each first positive feedback in each trial series of the WCST would also release attentional resources devoted to the online monitoring of task demands. This interpretation is consistent with the context updating model of the P3 component (Donchin \& Coles, 1988; Donchin, Karis, Bashore, Coles, \& Gratton, 1986), which states that the P3 component indicates a reconfiguration of attention to meet changing task demands and requires a revision of a created representation of the environment.

\section{Conclusions}

Our results provide evidence for the important role of cognitive control processes in task switching. Distinct neural response patterns were observed, which were specifically associated with those cognitive operations. The neural dissociation of these cognitive operations is based largely on the effects in oscillatory activity, particularly in the beta-gamma band $(20-30 \mathrm{~Hz})$, which cannot be studied with ERPs. Our results revealed a contribution of 
reinforcement learning mechanisms driven by performance feedback. In summary, the present pattern of results sheds light on the neural mechanisms implicated in adjusting our behavior in response to environmental signals that provide information about the correctness of our decisions.

Acknowledgements This research was funded by the Volkswagen Foundation (awarded to T.F.M. and A.R.F). In addition, A.R.F. was supported by a grant from the Spanish (PSI2008-03901) and the Catalan (SGR 2009 SGR 93) governments. J.M.P. and L.F. were supported by the Ramon y Cajal program. U.M.K. and T.F.M. were supported by the Deutsche Forschungsgemeinschaft (DFG). T.F.M. was also supported by German Federal Ministry of Science (BMBF).

\section{References}

Adrover-Roig, D., \& Barceló, F. (2010). Individual differences in aging and cognitive control modulate the neural indexes of context updating and maintenance during task switching. Cortex, 46, 434-450

Axmacher, N., Cohen, M. X., Fell, J., Haupt, S., Dumpelmann, M., Elger, C. E., . . . Ranganath, C. (2010). Intracranial EEG correlates of expectancy and memory formation in the human hippocampus and nucleus accumbens. Neuron, 65, 541-549.

Badre, D., \& Wagner, A. D. (2006). Computational and neurobiological mechanisms underlying cognitive flexibility. Proceedings of the National Academy of Sciences, 103, 7186-7191.

Baker, S. N. (2007). Oscillatory interactions between sensorimotor cortex and the periphery. Current Opinion in Neurobiology, 17, 649-655.

Barceló, F., Periañez, J. A., \& Knight, R. T. (2002). Think differently: A brain orienting response to task novelty. NeuroReport, 13, $1887-1892$.

Barceló, F., Periañez, J. A., \& Nyhus, E. (2007). An information theoretical approach to task-switching: Evidence from cognitive brain potentials in humans. Frontiers in Human Neuroscience, 1, 13.

Berke, J. D. (2009). Fast oscillations in cortical-striatal networks switch frequency following rewarding events and stimulant drugs. European Journal of Neuroscience, 30, 848-859.

Berns, G. S., McClure, S. M., Pagnoni, G., \& Montague, P. R. (2001). Predictability modulates human brain response to reward. Journal of Neuroscience, 21, 2793-2798.

Botvinick, M. M., Braver, T. S., Barch, D. M., Carter, C. S., \& Cohen, J. D. (2001). Conflict monitoring and cognitive control. Psychological Review, 108, 624-652.

Brass, M., Ullsperger, M., Knoesche, T. R., von Cramon, D. Y., \& Phillips, N. A. (2005). Who comes first? The role of the prefrontal and parietal cortex in cognitive control. Journal of Cognitive Neuroscience, 17, 1367-1375.

Braver, T. S., \& Ruge, H. (2005). Functional neuroimaging of executive functions. In R. Cabeza \& A. Kingstone (Eds.), Handbook of functional neuroimaging of cognition (pp. 307348). Cambridge: MIT Press.

Brown, P., Oliviero, A., Mazzone, P., Insola, A., Tonali, P., \& Di Lazzaro, V. (2001). Dopamine dependency of oscillations between subthalamic nucleus and pallidum in Parkinson's disease. Journal of Neuroscience, 21, 1033-1038.

Bunzeck, N., Guitart-Masip, M., Dolan, R. J., \& Düzel, E. (2011). Contextual novelty modulates the neural dynamics of reward anticipation. Journal of Neuroscience, 31, 12816-12822.

Burgess, P. W., Veitch, E., de Lacy, C. A., \& Shallice, T. (2000). The cognitive and neuroanatomical correlates of multitasking. Neuropsychologia, 38, 848-863.
Càmara, E., Rodríguez-Fornells, A., \& Münte, T. F. (2010). Microstructural brain differences predict functional hemodynamic responses in a reward processing task. Journal of Neuroscience, 30, 11398-11402.

Càmara, E., Rodríguez-Fornells, A., Ye, Z., \& Münte, T. F. (2009). Reward networks in the brain as captured by connectivity measures. Frontiers in Neuroscience, 3, 350-362.

Cavanagh, J. F., Cohen, M. X., \& Allen, J. J. (2009). Prelude to and resolution of an error: EEG phase synchrony reveals cognitive control dynamics during action monitoring. Journal of Neuroscience, 29, 98-105.

Cavanagh, J. F., Frank, M. J., Klein, T. J., \& Allen, J. J. B. (2010). Frontal theta links prediction errors to behavioral adaptation in reinforcement learning. NeuroImage, 49, 3198-3209.

Chase, H. W., Swainson, R., Durham, L., Benham, L., \& Cools, R. (2011). Feedback-related negativity codes prediction error but not behavioral adjustment during probabilistic reversal learning. Journal of Cognitive Neuroscience, 23, 936-946.

Chwilla, D. J., \& Brunia, C. H. (1991). Event-related potentials to different feedback stimuli. Psychophysiology, 28, 123-132.

Cohen, M. X., Elger, C. E., \& Ranganath, C. (2007). Reward expectation modulates feedback-related negativity and EEG spectra. NeuroImage, 35, 968-978.

Cohen, M. X., \& Ranganath, C. (2007). Reinforcement learning signals predict future decisions. Journal of Neuroscience, 27, 371-378.

Courtemanche, R., Fujii, N., \& Graybiel, A. M. (2003). Synchronous, focally modulated beta-band oscillations characterize local field potential activity in the striatum of awake behaving monkeys. Journal of Neuroscience, 23, 11741-11752.

Damasio, A. R. (1995). On some functions of the human prefrontal cortex. Annals of the New York Academy of Sciences, 769, 241251.

De Swart, J. H., Kok, A., \& Das-Smaal, E. A. (1981). P300 and uncertainty reduction in a concept-identification task. Psychophysiology, 18, 619-629.

Delorme, A., Westerfield, M., \& Makeig, S. (2007). Medial prefrontal theta bursts precede rapid motor responses during visual selective attention. Journal of Neuroscience, 27, 11949-11959.

Doñamayor, N., Marco-Pallarès, J., Heldmann, M., Schoenfeld, M. A., \& Münte, T. F. (in press). Temporal dynamics of reward processing revealed by magnetoencephalography. Human Brain Mapping. doi:10.1002/hbm.21184

Donchin, E., \& Coles, M. G. (1988). Is the P300 component a manifestation of context updating? The Behavioral and Brain Sciences, 11, 357-427.

Donchin, E., Karis, D., Bashore, T. R., Coles, M. G. H., \& Gratton, G. (1986). Cognitive psychophysiology and human information processing. In M. G. H. Coles, E. Donchin, \& S. W. Porges (Eds.), Psychophysiology: Systems, processes, and applications (pp. 244-267). New York: Guilford.

Dreher, J. C., Kohn, P., \& Berman, K. F. (2006). Neural coding of distinct statistical properties of reward information in humans. Cerebral Cortex, 16, 561-573.

Engel, A. K., \& Fries, P. (2010). Beta-band oscillations-signalling the status quo? Current Opinion in Neurobiology, 20, 156-165.

Eppinger, B., Kray, J., Mock, B., \& Mecklinger, A. (2008). Better or worse than expected? Aging, learning, and the ERN. Neuropsychologia, 46, 521-539.

Furumoto, H. (1991). P300 as a reflection of a mental set-P300 in the paradigm of Wisconsin Card Sorting Test. No To Shinkei, 43, 1047-1052.

Gehring, W. J., \& Willoughby, A. R. (2004). Are all medial frontal negativities created equal? Toward a richer empirical basis for theories of action monitoring. In M. Ullsperger \& M. Falkenstein (Eds.), Errors, conflicts and the brain: Current opinions on 
performance monitoring (pp. 14-20). Leipzig: Max Planck Institute of Cognitive Neuroscience.

Gevins, A., Smith, M. E., McEvoy, L., \& Yu, D. (1997). Highresolution EEG mapping of cortical activation related to working memory: Effects of task difficulty, type of processing, and practice. Cerebral Cortex, 7, 374-385.

Gilbert, S. J., \& Shallice, T. (2002). Task switching: A PDP model. Cognitive Psychology, 44, 297-337.

Gladwin, T. E., \& de Jong, R. (2005). Bursts of occipital theta and alpha amplitude preceding alternation and repetition trials in a task-switching experiment. Biological Psychology, 68, 309-329.

Grafman, J., \& Litvan, I. (1999). Importance of deficits in executive functions. Lancet, 354, 1921-1923.

Haji Hosseini, A., Rodríguez-Fornells, A., \& Marco-Pallares, J. (2011). The role of beta-gamma oscillatory activity in reward processing. Manuscript submitted for publication.

Hallschmid, M., Molle, M., Fischer, S., \& Born, J. (2002). EEG synchronization upon reward in man. Clinical Neurophysiology, 113, 1059-1065.

Haschke, W., Haschke, R., Schwind, J., Dormann, S., \& Dormann, W. U. (1985). Reevaluation: A systematic approach by means of event-related potentials (ERPs). In F. Klix, R. Näätänen, \& K. Zimmer (Eds.), Psychophysiological approaches to human information processing (pp. 237-245). Amsterdam: Elsevier.

Heaton, R. K. (1981). The Wisconsin Card Sorting Test manual. Odessa: Psychological Assessment Resources.

Heaton, R. K., Chelune, G. J., Talley, J. L., Kay, E. G., \& Curtiss, G. (1993). Wisconsin Card Sorting Test manual revised and expanded. Odessa: Psychological Assessment Resources.

Holroyd, C. B., \& Coles, M. G. (2002). The neural basis of human error processing: Reinforcement learning, dopamine, and the error-related negativity. Psychological Review, 109, 679-709.

Holroyd, C. B., Pakzad-Vaezi, K. L., \& Krigolson, O. E. (2008). The feedback correct-related positivity: Sensitivity of the eventrelated brain potential to unexpected positive feedback. Psychophysiology, 45, 688-697.

Hsieh, S., \& Liu, L. C. (2005). The nature of switch cost: Task set configuration or carry-over effect? Cognitive Brain Research, 22, $165-175$.

Jennings, J. R., \& Wood, C. C. (1976). Epsilon-adjustment procedure for repeated-measures analyses of variance. Psychophysiology, 13, 277-278.

Jimura, K., Locke, H. S., \& Braver, T. S. (2010). Prefrontal cortex mediation of cognitive enhancement in rewarding motivational contexts. Proceedings of the National Academy of Sciences, 107, $8871-8876$.

Johnson, R., Jr. (1986). A triarchic model of P300 amplitude. Psychophysiology, 23, 367-384.

Johnson, R., Jr., \& Donchin, E. (1978). On how P300 amplitude varies with the utility of the eliciting stimuli. Electroencephalography and Clinical Neurophysiology, 44, 424-437.

Jost, K., Mayr, U., \& Rosler, F. (2008). Is task switching nothing but cue priming? Evidence from ERPs. Cognitive, Affective, \& Behavioral Neuroscience, 8, 74-84.

Kalenscher, T., Lansink, C. S., Lankelma, J. V., \& Pennartz, C. M. (2010). Reward-associated gamma oscillations in ventral striatum are regionally differentiated and modulate local firing activity. Journal of Neurophysiology, 103, 1658-1672.

Kieffaber, P. D., \& Hetrick, W. P. (2005). Event-related potential correlates of task switching and switch costs. Psychophysiology, $42,56-71$

Kim, H., Shimojo, S., \& O'Doherty, J. P. (2006). Is avoiding an aversive outcome rewarding? Neural substrates of avoidance learning in the human brain. PLoS Biology, 4, e233.

Knutson, B., Fong, G. W., Bennett, S. M., Adams, C. M., \& Hommer, D. (2003). A region of mesial prefrontal cortex tracks monetarily rewarding outcomes: Characterization with rapid event-related fMRI. NeuroImage, 18, 263-272.

Konishi, S., Nakajima, K., Uchida, I., Kameyama, M., Nakahara, K., Sekihara, K., \& Miyashita, Y. (1998). Transient activation of inferior prefrontal cortex during cognitive set shifting. Nature Neuroscience, 1, 80-84.

Kopp, B., Tabeling, S., Moschner, C., \& Wessel, K. (2006). Fractionating the neural mechanisms of cognitive control. Journal of Cognitive Neuroscience, 18, 949-965.

Kotchoubey, B. (2002). Do event-related brain potentials reflect mental (cognitive) operations? Journal of Psychophysiology, 16, 129-149.

Kouneiher, F., Charron, S., \& Koechlin, E. (2009). Motivation and cognitive control in the human prefrontal cortex. Nature Neuroscience, 12, 939-945.

Lai, G., \& Mangels, J. A. (2007). Cueing effects on semantic and perceptual categorization: ERPs reveal differential effects of validity as a function of processing stage. Neuropsychologia, 45, 2038-2050.

Lalo, E., Thobois, S., Sharott, A., Polo, G., Mertens, P., Pogosyan, A., \& Brown, P. (2008). Patterns of bidirectional communication between cortex and basal ganglia during movement in patients with Parkinson disease. Journal of Neuroscience, 28, 3008-3016.

Locke, H. S., \& Braver, T. S. (2008). Motivational influences on cognitive control: Behavior, brain activation, and individual differences. Cognitive, Affective, \& Behavioral Neuroscience, 8 , 99-112.

Logan, G. D. (1985). Executive control of thought and action. Acta Psychologica, 60, 193-210.

Luks, T. L., Simpson, G. V., Feiwell, R. J., \& Miller, W. L. (2002). Evidence for anterior cingulate cortex involvement in monitoring preparatory attentional set. NeuroImage, 17, 792-802.

Luu, P., Shane, M., Pratt, N. L., \& Tucker, D. M. (2009). Corticolimbic mechanisms in the control of trial and error learning. Brain Research, 1247, 100-113.

Luu, P., Tucker, D. M., \& Makeig, S. (2004). Frontal midline theta and the error-related negativity: Neurophysiological mechanisms of action regulation. Clinical Neurophysiology, 115, 1821-1835.

Makeig, S., Delorme, A., Westerfield, M., Jung, T. P., Townsend, J., Courchesne, E., \& Sejnowski, T. J. (2004). Electroencephalographic brain dynamics following manually responded visual targets. PLoS Biology, 2, e176.

Makeig, S., Westerfield, M., Jung, T. P., Covington, J., Townsend, J., Sejnowski, T. J., \& Courchesne, E. (1999). Functionally independent components of the late positive event-related potential during visual spatial attention. Journal of Neuroscience, $19,2665-2680$.

Marco-Pallarès, J., Cucurell, D., Cunillera, T., Garcia, R., AndresPueyo, A., Münte, T. F., \& Rodríguez-Fornells, A. (2008). Human oscillatory activity associated to reward processing in a gambling task. Neuropsychologia, 46, 241-248.

Marco-Pallarès, J., Cucurell, D., Cunillera, T., Krämer, U. M., Càmara, E., Nager, W., . . . Rodríguez-Fornells, A. (2009). Genetic variability in the dopamine system (dopamine receptor D4, Catechol-O-Methyltransferase) modulates neurophysiological responses to gains and losses. Biological Psychiatry, 66, 154.

Marco-Pallarès, J., Cucurell, D., Münte, T. F., Strien, N., \& Rodríguez-Fornells, A. (2011). On the number of trials needed for a stable feedback-related negativity. Psychophysiology, 48, $852-860$.

Meiran, N. (1996). Reconfiguration of processing mode prior to task performance. Journal of Experimental Psychology: Learning, Memory, and Cognition, 22, 1423-1442.

Miller, E. K., \& Cohen, J. D. (2001). An integrative theory of prefrontal cortex function. Annual Review of Neuroscience, 24, 167-202. 
Milner, B. (1963). Effects of different brain lesions on card sorting. Archives of Neurology, 9, 90-100.

Monchi, O., Petrides, M., Petre, V., Worsley, K., \& Dagher, A. (2001). Wisconsin card sorting revisited: Distinct neural circuits participating in different stages of the task identified by event-related functional magnetic resonance imaging. Journal of Neuroscience, $21,7733-7741$.

Monsell, S. (2003). Task switching. Trends in Cognitive Sciences, 7, $134-140$

Müller, S. V., Moller, J., Rodríguez-Fornells, A., \& Münte, T. F. (2005). Brain potentials related to self-generated and external information used for performance monitoring. Clinical Neurophysiology, 116, 63-74.

Nagahama, Y., Fukuyama, H., Yamauchi, H., Katsumi, Y., Magata, Y., Shibasaki, H., \& Kimura, J. (1997). Age-related changes in cerebral blood flow activation during a card sorting test. Experimental Brain Research, 114, 571-577.

Nicholson, R., Karayanidis, F., Poboka, D., Heathcote, A., \& Michie, P. T. (2005). Electrophysiological correlates of anticipatory taskswitching processes. Psychophysiology, 42, 540-554.

Nieuwenhuis, S., Ridderinkhof, K. R., Talsma, D., Coles, M. G., Holroyd, C. B., Kok, A., \& van der Molen, M. W. (2002). A computational account of altered error processing in older age: Dopamine and the error-related negativity. Cognitive, Affective, \& Behavioral Neuroscience, 2, 19-36.

Nieuwenhuis, S., Slagter, H. A., von Geusau, N. J., Heslenfeld, D. J., \& Holroyd, C. B. (2005). Knowing good from bad: Differential activation of human cortical areas by positive and negative outcomes. European Journal of Neuroscience, 21, 3161-3168.

Norman, D., \& Shallice, T. (1986). Attention to action: Willed and automatic control of behavior. In R. Davidson, G. Schwartz, \& D. Shapiro (Eds.), Consciousness and self regulation: Advances in research and theory (pp. 1-18). New York: Plenum.

Passingham, R. E. (1993). The frontal lobes and Voluntary action. New York: Oxford University Press.

Periañez, J. A., \& Barceló, F. (2009). Updating sensory versus task representations during task-switching: Insights from cognitive brain potentials in humans. Neuropsychologia, 47, 1160-1172.

Periañez, J. A., Maestu, F., Barceló, F., Fernandez, A., Amo, C., \& Ortiz, A. T. (2004). Spatiotemporal brain dynamics during preparatory set shifting: MEG evidence. NeuroImage, 21, 687-695.

Posner, M. I., \& Petersen, S. E. (1990). The attention system of the human brain. Annual Review of Neuroscience, 13, 25-42.

Potts, G. F., \& Tucker, D. M. (2001). Frontal evaluation and posterior representation in target detection. Cognitive Brain Research, 11, $147-156$.

Ridderinkhof, K. R., van den Wildenberg, W. P., Segalowitz, S. J., \& Carter, C. S. (2004). Neurocognitive mechanisms of cognitive control: The role of prefrontal cortex in action selection, response inhibition, performance monitoring, and reward-based learning. Brain and Cognition, 56, 129-140.

Rogers, R. D., \& Monsell, S. (1995). The costs of a predictable switch between simple cognitive tasks. Journal of Experimental Psychology. General, 124, 207-231.

Rushworth, M. F., Passingham, R. E., \& Nobre, A. C. (2002). Components of switching intentional set. Journal of Cognitive Neuroscience, 14, 1139-1150.

Sarnthein, J., Petsche, H., Rappelsberger, P., Shaw, G. L., \& von Stein, A. (1998). Synchronization between prefrontal and posterior association cortex during human working memory. Proceedings of the National Academy of Sciences, 95, 7092-7096.

Sauseng, P., Klimesch, W., Freunberger, R., Pecherstorfer, T., Hanslmayr, S., \& Doppelmayr, M. (2006). Relevance of EEG alpha and theta oscillations during task switching. Experimental Brain Research, 170, 295-301.

Savine, A. C., \& Braver, T. S. (2010). Motivated cognitive control: Reward incentives modulate preparatory neural activity during task-switching. Journal of Neuroscience, 30, 10294-10305.

Shallice, T. (1988). From neuropsychology to mental structure. Cambridge: Cambridge University Press.

Slagter, H. A., Kok, A., Mol, N., Talsma, D., \& Kenemans, J. L. (2005). Generating spatial and nonspatial attentional control: An ERP study. Psychophysiology, 42, 428-439.

Steriade, M. (2006). Grouping of brain rhythms in corticothalamic systems. Neuroscience, 137, 1087-1106.

Stuss, D. T., \& Benson, D. F. (1986). The frontal lobes. New York: Raven.

Stuss, D. T., \& Picton, T. W. (1978). Neurophysiological correlates of human concept formation. Behavioral Biology, 23, 135-162.

Stuss, D. T., Shallice, T., Alexander, M. P., \& Picton, T. W. (1995). A multidisciplinary approach to anterior attentional functions. Annals of the New York Academy of Sciences, 769, 191-211.

Swainson, R., Jackson, S. R., \& Jackson, G. M. (2006). Using advance information in dynamic cognitive control: An ERP study of task-switching. Brain Research, 1105, 61-72.

Tallon-Baudry, C., Bertrand, O., Delpuech, C., \& Permier, J. (1997). Oscillatory gamma-band $(30-70 \mathrm{~Hz})$ activity induced by a visual search task in humans. Journal of Neuroscience, 17, 722-734.

Tom, S. M., Fox, C. R., Trepel, C., \& Poldrack, R. A. (2007). The neural basis of loss aversion in decision-making under risk. Science, 315, 515-518.

van de Vijver, I., Ridderinkhof, K., \& Cohen M. X. (in press). Frontal oscillatory dynamics predict feedback learning and action adjustment. Journal of Cognitive Neuroscience.

van der Meer, M. A. A., \& Redish, A. D. (2010). Low and high gamma oscillations in rat ventral striatum have distinct relationships to behavior, reward, and spiking activity on a learned spatial decision task. Frontiers in Integrative Neuroscience, 3, 1-19.

van Veen, V., \& Carter, C. S. (2002). The anterior cingulate as a conflict monitor: fMRI and ERP studies. Physiology \& Behavior, $77,477-482$.

Varela, F., Lachaux, J. P., Rodriguez, E., \& Martinerie, J. (2001). The brainweb: Phase synchronization and large-scale integration. Nature Reviews Neuroscience, 2, 229-239.

Verstraeten, E., \& Gluydts, R. (2002). Attentional switching-related human EEG alpha oscillations. NeuroReport, 13, 681-684.

Volz, H. P., Gaser, C., Hager, F., Rzanny, R., Mentzel, H. J., Kreitschmann-Andermahr, I., . . . Sauer, H. (1997). Brain activation during cognitive stimulation with the Wisconsin Card Sorting Test-a functional MRI study on healthy volunteers and schizophrenics. Psychiatry Research, 75, 145157.

Watson, T. D., Azizian, A., \& Squires, N. K. (2006). Event-related potential correlates of extradimensional and intradimensional setshifts in a modified Wisconsin Card Sorting Test. Brain Research, 1092, 138-151.

Womelsdorf, T., Johnston, K., Vinck, M., \& Everling, S. (2010). Theta-activity in anterior cingulate cortex predicts task rules and their adjustments following errors. Proceedings of the National Academy of Sciences, 107, 5248-5253.

Yeung, N., \& Monsell, S. (2003). The effects of recent practice on task switching. Journal of Experimental Psychology. Human Perception and Performance, 29, 919-936.

Yordanova, J., Falkenstein, M., Hohnsbein, J., \& Kolev, V. (2004). Parallel systems of error processing in the brain. NeuroImage, 22, 590-602. 